\section{LA BIOÉTICA JURÍDICA ISLÁMICA COMO FENÓMENO JURÍDICO-CULTURAL REGIONAL: TENSIONES INTERNAS Y \\ EXTERNAS EN LA ACTUALIDAD PRODUCIDAS EN SU INSERCIÓN COMO DERECHOS HUMANOS}

\author{
Dr. Emilio Mikunda Franco' \\ (Universidad de Sevilla)
}

\author{
ISLAMIC LEGAL BIOETHICS AS \\ A REGIONAL PHAENOMENON \\ OF LEGAL CULTURE: INNER \\ AND OUTER TENSIONS \\ NOWADAYS AS A RESULT OF \\ ITS CONSIDERATION A SHUMAN \\ RIGHTS
}

\begin{abstract}
This paper is the third Part of a Trilogy around the socalled Islamic World. It presents us the "Islamic bioethics" as a legal regional phenomenon instead of an international one, as believed in the West World. It contains a glossary sui generis with specifically Islamic connotations. It means, with similarities and differences far away from the usefully ones in the West World and Spain, so that a big amount of mistakes of interpretation can be avoided, because the aimed words are written in similar way but with very different signification. The paper analyzes the tensions produced in and outside of the Islamic World by associating bioethics and human rights. Such a situation reproduces -in the meaning of the author-another old problem up-to-day not resolved, the so-called "Universal human rights versus regional Islamic human rights". A selected bibliography in the end contains specifically themes of human rights, Islamic bioethics and constitutionalism, and finally the own contributions of the author.
\end{abstract}

KEY WORDS: Bioethics; theoretical judicial bioethics; islamic bioethics; bioethics and religion; Common Islamic Constitutional Law; islamic human rights; laicism human rights; regional human rights; universal human rights; human dignity; islamic dignity; islamic(s) feminism(s); philosophy of law; glossary of islamic bioethics; islamic jurisprudence; theory of the islamic law and rights; terms of islamic bioethics.

\section{Proemio}

El presente estudio comparatista expone una paleta de perspectivas iusculturales existentes en la actualidad en el Mundo islámico - y algunas culturas aledañas- en materias de bioética islámica, tanto en el contexto de los Ilamados derechos humanos islámicos como en el homónimo de los laicos existentes ope legis en ciertos
RESUMEN: El presente trabajo corona la tercera parte de una trilogía en torno al Mundo islámico, tratando la "bioética jurídica islámica" como fenómeno jurídico regional frente a la occidental, autodenominada universal. (Anteriores partes fueron "Derechos humanos", y "constitucionalismo" islámicos.) Aporta un glosario terminológico islámico sui generis con connotaciones específicas, similitudes y diferencias frente a la occidental al uso en España, en evitación de posibles confusiones o lapsos debidos al uso de términos de idéntico significante y homólogo significado. Analiza tensiones de todo tipo producidas al asociar "bioética y derechos humanos en el mundo islámico". Condensa en diez tesis finales la polémica y problemática resultante, que reproduce -según su autor- análoga situación de otrora entre "Derechos humanos universales versus Derechos humanos islámicos regionales". La bibliografía selectiva abarca temas específicos de Derechos humanos, bioética islámica y constitucionalismo, reseñando in fine aportaciones del autor.

PALABRAS CLAVE: Bioética; bioética jurídica; bioética jurídica islámica; bioética y religión; Derecho Constitucional Común islámico; derechos humanos; derechos humanos islámicos; derechos humanos laicos; derechos humanos regionales; derechos humanos universales; dignidad humana; dignidad islámica; feminismo(s) islámico(s); filosofía del derecho; glosas básicas de bioética islámica; jurisprudencia islámica; teoría del Derecho islámico; terminología bioética islámica.

países y Estados del Mundo islámico, mediante una exposición que pretende reflejarlos tanto como fuente de tensiones internas, -léase las producidas a nivel interconfesional islámico-, como externas -léase frente a Occidente y a otras culturas no-occidentales-, completando y ampliando en su caso aspectos ético-jurídicos esbozados prima facie en el capítulo decimonono del libro colectivo más reciente ${ }^{2}$ de la Universidad de Sevilla: 
Ética de la vida y la salud: Su problemática biojurídica, libro formado por otras dieciocho aportaciones propias del ámbito cultural hispano-occidental que nos servirán de enmarque y cotejo de las posturas mencionadas a lo largo del presente trabajo. No obstante debemos indicar que la temática básica del susodicho capitulo supone tan sólo una aproximación al tema: "Aspectos de Bioética en el Mundo islámico contemporáneo", tema que ya habíamos esbozado de forma tan concisa como densa en la ponencia "La bioética islámica como paradigma jurídico-cultural contemporáneo", pronunciada en el marco de las segundas jornadas de la razón jurídica, surgidas bajo el lema: "Globalización jurídica y paradigmas culturales", organizadas por el Grupo de Estudios Lógico-Juridicos del Instituto de Filosofía del CSIC de Madrid, bajo la dirección del Prof. Dr. Lorenzo Peña el 20 abril 2007, reiterada más recientemente en La Hispalense como "La bioética jurídica como Derecho humano islámico en la actualidad", en noviembre de 2008. Ahora bien, el presente trabajo va más allá todavía e involucra además, y como cotejo contrapuntístico, aspectos insoslayables de la problemática bioética que dimana de posturas iusculturales occidentales, -en parte preferentemente españolas-, que surgen inevitablemente al incluir las tesis reseñadas en la variada paleta temática que a lo largo de los dieciocho capítulos vertebran el susodicho texto, tomado ahora como paradigma básico de reflexión y referencia principal, aparte de incluir otras consideraciones conexas e igualmente insoslayables en el ámbito islámico contemporáneo como el todavía incipiente "feminismo islámico" de aspectos multidimensionales. Esta nueva e incontrovertible realidad, se hace visible, sobre todo, a través de su proyección -más sociológica que normativamente relevante hoy por hoy-, en aquellos aspectos bioéticos propios del progresivo rol que va ocupando poco a poco la mujer en las sociedades islámicas y de los que resulta prácticamente indisociable en un doble y simultáneo plano: sea para apoyar la modernidad, sea para retraerse a posturas más tradicionales, jalonado todo ello con el contrapunto que nos permite la inserción de aquellas posturas doctrinales y constitucionalistas procedentes sobre todo de la UE e lberoamérica, que lúcidamente expuestas, han sido recogidas por el profesor Francisco Fernández Segado en su más reciente publicación ${ }^{3}$ de abril 2008, que abarca una paleta de trece paises ${ }^{4}$ y treinta y ocho autores de alta relevancia.

\section{Antecedentes, metodologías, definiciones Y COHERENCIA SISTÉMICA}

1. Intentar exponer un tema de bioética islámica considerándola un fenómeno jurídico-cultural o iuscultural de cuño "regional" -cuando estamos saturados de oir hablar en nuestro contorno cultural preferentemente de la "universalización" del Derecho en su faceta global de Derechos Humanos "universales"5 - parece una empresa casi imposible $^{6}$ abocada al fracaso ${ }^{7}$. Por este motivo urge insistir en que desde hace ya casi una década hemos venido planteando paralelamente la posibilidad de contemplar los derechos humanos "también" como un "fenómeno cultural regional", al constatar que así es como realmente se entienden en el mundo globalmente considerado, es decir, independientemente de su adscripción sólo a Occidente, ya que la postura universalista es la que normalmente se halla implícita en cualquier exposición propia de nuestras latitudes de la forma más natural ${ }^{8}$ (tanto que ni siquiera se plantea la posibilidad de que pudieran existir de hecho otras alternativas, como asi es) $)^{9}$. Ahora bien, hacerlo así no presupone adscribirnos a ninguna rama actual de lo que se denomina sociologismo jurídico ${ }^{10}$ contemporáneo, si bien de momento nuestra exposición, únicamente, se ha limitado a su presentación y discusión por parte del alumnado italiano a través de la Universidad de Bolonia mediante su inserción en la revista "Scienza e Política", en la que apareció publicada en 2003, aprovechando la oportunidad que nos brindaba una petición por parte del profesor Gustavo Gozzi" ${ }^{11}$. Tras el éxito de esta empresa la completamos un año más tarde dentro del contexto relativo a lo que hemos denominado "Derecho Constitucional Común Islámico"12, un término creado por nosotros ex novo en franco paralelismo a la terminología iusfilosófico-constitucionalista del prestigioso pensador alemán Peter Häberle, cuya obra analizada desde premisas de la experiencia jurídica española pronto verá la luz editorial en España ${ }^{13}$.

Consecuentemente observamos que hoy en día se sigue produciendo un fenómeno similar globalmente considerado en el Mundo islámico a la hora de hablar de derechos humanos, al constatarse una tensión existente entre los partidarios de los alli llamados "derechos humanos de corte occidental o laico" y los partidarios de los "derechos humanos de corte genuinamente islámico", ya que éstos representan, hoy por hoy, la mayor proyección social y estatal a la vez respecto del Derecho islámico con- 
temporáneo, cuyas raíces teóricas se apoyan en fuentes jurisprudenciales netamente islámicas, siendo aplicados ope legis por jueces (Alfaquíes) y magistrados Islámicos (Cadies) incardinados en los respectivos ordenamientos jurídico-estatales. Por todo ello -y siempre en este contexto- conviene perfilar ideas y completar estructuras epistemológicas recordando que al movernos siempre en el seno del Derecho Islámico, en cualquier sentencia o laudo arbitral, o incluso cualquier consulta o dictamen jurídico (Fatwas), vinculante o no, se hallan indisociablemente unidos no sólo la moral religiosa y el derecho, con las implicaciones políticas que indisolublemente conlleva, sino asimismo todos los pilares de la llamada "Ciencia jurídica islámica", por lo que tales documentos no sólo deben contener los principios prescritos por las fuentes del Derecho Islámico (el Furu-al-Fiq) sino basarse asimismo en la "metodología Islámica" en cuanto a formas, procedimientos, recursos, etc. (Usul-al-Fiq), que es justamente una de las fuentes donde se producen tensiones entre juristas "islamizados" y juristas "occidentalizados", rara vez resueltas en una sintesis conciliadora de ambas posturas, siempre deseable. Si los primeros reprochan a los segundos padecer de "occidentalosis"14, los segundos atildan a los primeros de "retrógrados", generándose a veces un nefasto desencuentro.

Simultáneamente se observa hoy asimismo que tanto "los derechos humanos" como sus "aspectos bioéticos" se apoyan en conceptos multiseculares y multiculturales de límites relativamente difusos a lo largo de todo el planeta, un hecho fácilmente constatable, a la vez que resultan interrelacionados. Así, en uno de los más recientes trabajos de Peter Häberle publicados en España sobre "la dignidad del ser humano como fundamento de las comunidades estatales"15, este autor alemán de reconocida relevancia a nivel quasi-mundial reserva sus reflexiones más brillantes, presentadas a modo de "digresión", para relatar tres ejemplos actuales de la problemática de la dignidad humana bajo la Ley Fundamental alemana, hablando en primer lugar de "la fecundación artificial" y de "la tecnología genética" concluyendo con "el derecho a morir con dignidad", al que denomina "nuevo desafío para el artículo primero de la Constitución alemana vigente, como trasfondo de los cambios sociales y técnicos"16. Ni que decir tiene que el breve tenor literal de la Ley Fundamental alemana afirma tan categórica como lapidariamente que "La dignidad humana es intangible"17.
De ahí que resulte por tanto insoslayable recordar que el presente trabajo, necesariamente denso y en franca exposición panorámica, se incardina como tercera parte inescindible de una "amplia trilogía" cuyas líneas maestras, metodologías y antecedentes, fueron expuestas en los siguientes trabajos anteriores; 1. El libro: Derechos Humanos y Mundo islámico, -de amplia repercusión en España y parte de Europa, como así lo hemos mostrado- ${ }^{18}$; 2. Un amplio estudio subsiguiente -complementario-que desarrolla ampliamente algunos de los apartados de los capítulos quinto y sexto del citado libro, a saber, el "Derecho Constitucional Común islámico", contrapartida asimétrica al "Derecho Constitucional Común Europeo" häberliano, y "Elementos configuradores del Derecho islámico contemporáneo"19, del que hasta ahora todavía falta su traducción y exposición en español, pero del que no obstante existe una traducción parcial al italiano, del profesor Gozzi, -como antes señalamos- ${ }^{20}$.

Consecuentemente proseguiremos el presente estudio sobre bioética jurídica islámica considerada esta vez como un fenómeno jurídico-cultural regional, mostrando las tensiones internas y externas en la actualidad en el contexto de su inserción como derechos humanos con idéntica metodología por los buenos resultados que nos ha aportado, en franca coherencia sistémica con el resto de la susodicha trilogía.

\subsection{Metodologías}

Si en los trabajos anteriores ya citados ya habíamos insistido frecuentemente en que "hoy en día es indispensable llegar a un consenso a nivel de definición respecto del contenido material de cada uno de los 'derechos humanos' que se pretende elevar de hecho a universales"21 (pensando sobre todo en la praxis jurídica y social cotidiana de todos los paises y Estados del planeta independientemente de los substratos culturales de cada pueblo, buscando los "elementos comunes" a todos ellos como engarce de unión, de acuerdo con la metodología häberliana) ${ }^{22}$, igualmente recalcábamos la idea, -compartida por autores de países con múltiples visiones jurídicas- ${ }^{23}$, de que "se carece todavía de definiciones universalmente aceptadas en materia de derechos humanos" 24 . Pues bien, de nuevo hallamos aquí, en estas espinosas materias propias de la bioética -especialmente cuando se detecta en el seno del pensamiento jurídico genuino ínter islámico contemporáneo la existen- 
cia de diferentes corrientes, cuyos puntos de vista divergen entre sí en todo o en parte y no sólo frente a Occidente ${ }^{25}$, el mejor de los terrenos para ratificar nuevamente nuestra tesitura e invitar al lector a colaborar en la realización de este "improbo trabajo definitorio", todavía por hacer, de "raigambre transcultural" ética, filosófica, sociológica, antropológica, politológica; en suma, iusfilosófica ${ }^{26}$. Es obvio que sin detectar, al menos comparativamente, ciertos elementos comunes dentro de cada definición que se pretenda correcta frente a las demás, difícilmente se podrá salir del lamentable diálogo de sordos al que nos conducen los encontrados "-ismos" de todo tipo existentes hoy en día -integrismos, wahabismo, salafismo, tradicionalismos, laicismos, etc.- Consecuentemente el resultado de esta labor no puede ser sino uno consensuado entre todos, -cuando menos parcialmente-, dejando entre paréntesis el resto de sus elementos y características, en espera de lograr nuevos avances en estas delicadas materias, que al parecer van produciéndose paulatinamente debido a las reivindicaciones sobre todo del papel de la mujer ${ }^{27}$ en la sociedad contemporánea de los paises y estados confesionalmente islámicos ${ }^{28}$.

Precisamente la metodología comparatista moderna y posmoderna hoy al uso ofrece unos elementos óptimos como herramientas de trabajo ${ }^{29}$, al partir de la tolerancia, el diálogo, la aceptación de todos los interlocutores y de sus capacidades al más amplio nivel en cada materia, extrayendo conclusiones, siempre transitorias, a la espera de lograr algún día un consenso realmente definitivo y universa ${ }^{30}$ (algo que por otra parte suena a utópico de entrada, habida cuenta de la naturaleza humana tan proclive a la asunción de posturas individuales que se pretenden de proyección universal, fenómeno tan extendido como improbable de erradicar en un futuro a medio plazo). No puede por tanto extrañar que se pretenda aplicar aquí una metodología que ya se está aplicando desde hace años como la más correcta en estas espinosas cuestiones transculturales, como son todas las dimanantes de los amplísimos campos de la bioética y de las biotecnologías más recientes, habida cuenta que autores occidentales tan señeros en este campo de la reflexión como por ejemplo el español Juan Masià Clavel, ex director de la cátedra de bioética de la Universidad pontificia de Comillas, en uno de sus más lúcidos exámenes al respecto titulado Bioética y religión: una relación ambivalente ${ }^{31}$, adelanta una tesis que vamos a oír frecuentemente en el presente trabajo desde múltiples perspectivas juridico-culturales: "Hay obviamente muchas posturas en bioética; muchas bioéticas en plural (...) Según qué manera de pensar tengamos, tanto en bioética como en religión, abierta o estrecha, dialogante o fundamentalista, flexible o dogmática, será muy diferente la manera de ver la relación entre bioética y religión o entre ciencias biológicas y concepciones religiosas sobre la vida"32.

\subsection{Definiciones y coherencia sistémica}

En todo caso, el alud bibliográfico existente, tanto a lo largo de Occidente como del Mundo islámico (por inusual que pudiera parecer), en las diferentes materias de que consta hoy en día la Bioética, directamente referenciada tanto a nivel de legislación interna como constitucional efectuadas a través de tomar como referencia axiológica la dignidad humana especialmente ${ }^{33}$, muestra de plano, no sólo, la importancia que se atribuye a cada uno de sus aspectos y elementos, -por implicarnos directa o indirectamente a todos los seres humanos sin distinción alguna-, sino sobre todo porque, en virtud de su propia existencia, se ha hecho absolutamente imprescindible abrir y continuar permanentemente en el doble diálogo abierto intercultural-transcultural, que da la razón a la coexistencia y convivencia entre civilizaciones ${ }^{34}$, en vez de a la tesis de la burda lucha de civilizaciones a la que nos querían y quieren abocar ciertas corrientes de pensamiento muy concretas y minoritarias desde diversos campos del conocimiento ${ }^{35}$.

Una definición de bioética, -entendida en el Mundo islámico como aproximación a la propia bioética islámica-, nos la ofrecería el profesor libanés Boustany al decir: "la bioética estudia la utilización de técnicas nuevas en vistas a conciliar la investigación científica con la protección de la persona humana y su dignidad" ${ }^{\prime \prime}$; ahora bien, aunque no en el propio texto, sí en el contexto cultural en el que habla el autor y para poder entender por nuestra parte en Occidente la dimensión islámica de la bioética, acaso bastaría con añadir tan sólo a dicha definición la siguiente coletilla: "de acuerdo con los parámetros ético-jurídico-culturales existentes en el Mundo islámico" ${ }^{37}$, logrando integrar así lo regional islámico en el más amplio universo formado por el resto del mundo. La Bioética y la Jurisprudencia islámicas (que van de la mano en los paises islámicos de forma totalmente indisociable) quedan pues, contempladas en 
el seno que presenta a nuestros ojos el mundo desde una perspectiva interislámica, convertidas en "piedras de toque" de rabiosa actualidad para comprender el alcance y envergadura de estas materias, toda vez que en dicho mundo - al contrario de lo que sucede por lo general en Occidente-, los especialistas en cuestiones de bioética conocen en profundidad las fuentes islámicas del pensamiento jurídico -salvo excepciones- cuando menos a nivel teórico ${ }^{38}$ (al ser estudiadas como eje de las "Ciencias islámicas"), mientras que en Occidente, el conocimiento de "cuestiones con implicación bioética" suele estar bifurcado entre dos ámbitos de especialistas muy diferentes: Primero, el de los teólogos y expertos en las aquí denominadas "Ciencias Sociales" (filósofos, antropólogos, sociólogos, politólogos, etc. ${ }^{39}$ y segundo, en el de los especialistas en "Ciencias de la Salud" (médicos generalistas y colegas expertos en diferentes especialidades concretas, como ginecólogos, investigadores en biomedicina, etc. $)^{40}$. En ambos ámbitos y salvo rara excepción suele desconocerse "en profundidad" ratione materiae lo que podríamos denominar el entramado ético o las éticas subyacentes, -independientemente de dimanar todo ello, quizás, de la postura cultural religiosa tan occidental como dicotómica de "al César lo que es del César y a Dios lo que es de Dios"-, debido todo ello creemos a la propia configuración secular de la enseñanza universitaria del modelo europeo u occidental existente desde al menos el Renacimiento ${ }^{41}$. En este contexto no puede sorprender uno de los datos que más pueden corroborar esta tesis del "desdoblamiento" entre ciencias biomédicas y ciencias sociales existente en nuestra cultura occidental -insistimos en que constatable al menos desde el Renacimiento-. Tal dato se obtiene justo en el momento en que se pregunta a S.S. el Papa Pío XII al ser cuestionado directamente a contestar a partir de qué momento exacto se produce la muerte.

Masià nos lo recuerda de este modo: "Sobre el final de la vida preguntaban los anestesistas, en 1957, cómo define la Iglesia el momento de la muerte. Contestó Pio XII que es competencia del médico. Sin arrogarse la iglesia el derecho a definir científica o filosóficamente, recomendaba proteger la vida, pero dejaba a los profesionales determinar su final, actitud que no siempre se está manteniendo por el miedo a la pendiente resbaladiza de la eutanasia"42. Que tales temores "de miedo a la pendiente resbaladiza de la eutanasia" no eran, por otra parte, infundados nos lo recuerda el hecho de que hoy día en Occidente la especialización del lenguaje en este ámbito se ha producido ya por ejemplo en la especificación del concepto "eutanasia" diferenciando términos como la "distanasia" (obstinación terapéutica para mantener la vida cueste lo que cueste) y la "ortotanasia" (muerte casi natural al aplicar únicamente medios clínicos proporcionados) ${ }^{43}$, acercándonos así indirectamente y sin intercambio de información de ningún tipo a la propia realidad bioética islámica como más adelante comprobaremos en el correspondiente glosario básico.

Precisamente la existencia in crescendo de la propia Bioética ha vuelto a confrontar tan involuntaria como indirectamente en ambos mundos, occidental e islámico, las dos formas de entender el conocimiento científico humano: la occidental, preferente y tendencialmente laica, de separación entre lo religioso y lo científico; y la islámica, preferentemente también -aunque no sin posturas disidentes- ${ }^{44}$, de intima e indisociable unión (principio supremo del Tawhid) entre ambos ámbitos. De ahí que en bioética la "terminología islámica" sea de conocimiento tan fundamental como insoslayable, y de ahí que se sigan creando y remodelando de continuo términos posmodernos (p. ej. Xenotransplantes) que hace tan sólo algo más de dos décadas resultaban siquiera imposibles de vislumbrar. Hoy la definición a nivel iusfilosófico y lingüistico se hace necesaria más que nunca, ya que p. ej. ni siquiera está meridianamente claro a nivel intraislámico algo tan básico y obvio como el saber exactamente desde cuándo debe entenderse que el feto es persona humana (existiendo diferentes opiniones según cada escuela jurídica islámica) ${ }^{45} 0$ desde cuándo exactamente se produce la muerte ${ }^{46}$ (fenómeno que podemos comparar como similar a la perplejidad que produjeron las palabras de Pío XII en el catolicismo de los años cincuenta -como más arriba indicábamos- al no saberse tampoco con precisión). Aún más, resulta también imposible reconducir todos los términos al uso a un solo elenco claro e indubitable ${ }^{47}$, ya que sus diferentes connotaciones se hallan fuertemente auto imbricadas e interrelacionadas (así, p. ej. en los xenotransplantes pueden darse elementos de tejidos tomados de fetos, de células fecundadas in vitro y conservadas en frío, que pueden proceder de musulmanes o de no musulmanes - dato tan biomédico como bioético inconcebible, por supuesto, en Occidente- como veremos). 


\subsection{El valor divulgador y renovador de Internet en estas materias como fenómeno actual sin precedentes especialmente visible en los denominados movimientos feministas islámicos}

Finalmente, el valor actual de Internet ${ }^{48}$ es clave para poder seguir en vivo y en directo, o sea en tiempo real, el status quaestionis no sólo a nivel occidental, sino sobre todo a nivel de discusión intra islámica, existiendo portales especializados en prácticamente cada una de las lenguas que configuran básicamente la Unión Europea (francés, inglés, alemán y español) ${ }^{49}$. El fenómeno que se viene observando en los países islámicos, de consultar en cuestiones claves inherentes a la bioética y relacionadas con la vida cotidiana, -como p. ej. el tema del aborto, anticonceptivos, relaciones sexuales de pareja, etc., no sólo ya a los expertos en Ciencias islámicas (Ulamas, Alfaquies, Mufties, etc.)- sino incluso de obviar en parte sus opiniones y buscar la libertad de consulta individual personal a través de "opiniones de no-expertos" o sea, de cualquiera que encienda el ordenador y se conecte a la red, típicas de los denominados "chats" de Internet, -tras de los cuales ni siquiera aparece la identidad real de los participantes, sino únicamente pseudónimos, como en la mayoría de los blogs-, un fenómeno nuevo que viene a renovar y "descolocar" la arquitectura social de las fuentes de consulta tradicionales, reservadas durante siglos sólo a los expertos del Islam, añadiéndose así un elemento masivo de libertad de opinión posmoderna de nivel sociológico (frente al dogmático-tradicional), tan rechazado como combatido por los expertos islámicos (al parecer inútilmente dada la realidad del uso masivo de Internet por la población musulmana). En España concretamente podremos ver una de las mayores canalizaciones del fenómeno a través del denominado "feminismo islámico", cuyo primer "Congreso Internacional de Feminismo Islámico"50 nació con la vocación de dar a conocer el emergente movimiento de las mujeres musulmanas por la igualdad de sexo, y con el objetivo de establecer un diálogo con el movimiento feminista global. Abdenur Prado uno de sus más representativos coordinadores -tan polémico en España como en el propio Mundo islámico- indica: "Existe por tanto una búsqueda común que nos lleva a enfocar el asunto de la discriminación de la mujer musulmana desde un punto de vista universal, con el referente de los derechos humanos como fondo. Derechos humanos y sexuales, a crear y a decidir, a profesar las propias convicciones, a la libertad de expresión y de conciencia. Sin duda, estos son algunos de los derechos que el feminismo islámico reivindica, la recuperación de unos derechos usurpados a las mujeres musulmanas por una interpretación patriarcal y totalitaria del islam. A partir de aquí, es posible establecer la conexión del feminismo islámico con el movimiento feminista global"51.

Ahora bien, en el Mundo islámico $0^{52}$ todo jurista sabe que la llamada "doctrina legal islámica" repercute tanto a nivel de Derecho interno como del Internacional privado y público a la vez, de modo que el rol de jueces y magistrados, de doctores y jurisprudentes en Ciencias jurídicas islámicas (Ulamas) resultando así que la estructuración del poder judicial islámico viene a ser de todo punto un factor primordial para entender la proyección de los derechos humanos en el mundo Islámico, ya que es precisamente en este campo institucional donde actúan dichos jueces, un ámbito propio de conceptos, categorías e instituciones jurídicas, y donde se producen conflictos y colisiones específicas entre ciertos derechos humanos (p. ej. el del status coniugalis et matrimonialis,) no sólo frente a una concepción meramente aconfesional o laica, sino frente a cualquier otra confesionalidad religiosa no islámica, conflictos que serán tanto más intensos cuanto más se alejen de las religiones monoteistas reconocidas por el Islam, es decir, del judaísmo, zoroastrismo y cristianismo. Todos estos aspectos son hoy igualmente fundamentales en el ámbito de la bioética, siendo sus proyecciones a través de Internet especialmente relevantes como tales, como venimos manteniendo $0^{53}$.

Para más abundamiento, otra de las claves de la interrelación preferente hoy entre cuestiones de "Bioética y de Jurisprudencia islámica contemporáneas" nos la proporciona el II. ${ }^{\circ}$ Congreso de Feminismo Islámico celebrado en Barcelona y centrado en temas preferentemente bioéticos incluidos hoy en la Ley islámica o Sharià al igual que en los "códigos de familia" o Moudawannas ${ }^{54}$ laicos o quasi-lai$\cos ^{55}$ del mundo islámico. "El motivo es obvio: si hablamos de la lucha de las mujeres musulmanas contra la discriminación por razón de sexo, debemos analizar el contenido de estos códigos de familia, que en muchos aspectos son fuertemente discriminatorios. Hay que hablar del divorcio, de la poligamia, del aborto, de la segregación de los sexos, de la tutela del hombre sobre la mujer... de todos aquellos temas en los cuales las enseñanzas genuinas del Islam son distorsionadas"5. "Todo esto - prosigue- implica ser críti- 
cos con respecto a nuestra tradición jurídica, y reconocer que las grandes escuelas de jurisprudencia islámica fueron codificadas bajo los parámetros del patriarcado. No se trata de desechar el Fiq clásico, sino de realizar una aproximación crítica, que nos permita preservar lo más valioso de este legado inmenso. Esta revisión es hoy imprescindible. No podemos olvidar que existen movimientos políticos que reclaman la aplicación de la ley islámica tal y como fue codificada hace diez siglos, en un contexto totalmente diferente al nuestro, lo cual acaba significando una disminución de los derechos de las mujeres musulmanas" ${ }^{17}$.

\section{LA BIOÉTICA JURÍDICA ISLÁMICA COMO FENÓMENO IUSCULTURAL REGIONAL DE ACTUALIDAD}

Observamos por tanto que lo que se denomina "culturas jurídicas" no es sino la proyección de sus respectivas filosofías jurídicas subyacentes hecho de forma diferenciada. De ahí que lo que ha caracterizado a lo largo de la historia y sigue caracterizando a los ordenamientos jurídicos en el mundo contemporáneo no sea sino la antropología subyacente e implícita que todos ellos contienen, ya que dichos ordenamientos no son sino la proyección y "cristalización de los propios valores culturales" en torno a los que se estructuran las diferentes normas jurídicas e instituciones de que constan ${ }^{58}$. Este fenómeno ha sido muy sagazmente observado en Occidente sobre todo durante los últimos cien años, surgiendo toda una paleta de "teorías" en torno al Derecho, como la teoría tridimensional, la de la experiencia jurídica y la estructuralista del Derecho (por no citar sino las tres que consideramos hoy más relevantes). Todas ellas insisten en la necesidad de tener en cuenta los valores iusfilosóficos (léase culturales en este contexto) de cada sociedad o Estado dotado de ordenamiento jurídicoconstitucional, conditio sine qua non para captar lo esencial del mismo. Cuando se habla de Derechos humanos se sobreentiende que éstos poseen unos valores establecidos sobre unos fundamentos, fundamentos que por otra parte no son sino filosóficos de entrada, como resultado de movimientos culturales de más de dos milenios de antigüedad, que para unos son claramente de cuño positivo y para otros dados por la naturaleza. Así, el reputado jurista, catedrático de Derecho Público y magistrado alemán Christian Starck, en un texto muy recientemente traducido y publicado en España en abril 2008 bajo el título "Los fun- damentos filosóficos de los Derechos humanos", termina por constatar tras su recorrido exclusivamente por tierras europeas a partir del siglo XVIII, que tanto los textos constitucionales como los filosófico-literarios que tocan esta temática (y que en Alemania concretamente concluyen en la Ley Fundamental Alemana de 1948, en cuyo segundo párrafo se lee: "El pueblo alemán se identifica con los inviolables e inalienables derechos humanos como fundamento de toda la comunidad humana, de la paz y de la Justicia en el mundo", lo que significa que se remite a la Declaración Universal de Derechos Humanos de NN.UU de diciembre 1948), concluyen con una tesis de lo más polémica en Alemania, al reflejar la tensión subyacente entre partidarios del Derecho Natural y el positivo, decantándose por el primero: "Con este reconocimiento, el pueblo alemán ha partido de la tradición de los derechos humanos, los cuales se fundamentan en el Derecho Natural"59.

Ahora bien, como es sabido, cualquier tipo de normas jurídicas carentes de valores o de axiología resultan ser cajas vacías de contenido. Por otra parte es evidente que todavía no ha sido posible en el mundo contemporáneo y pese a todos los adelantos de nuestro siglo lograr una amplia plataforma consensual de "valores interculturales unánimemente compartidos" 60 , pese a los ingentes esfuerzos realizados, hecho que se evidencia sobre todo en los aspectos teórico-filosóficos del Derecho, una realidad implícita a nuestro mundo y tan tenaz que todavía sigue impidiendo y obstaculizando cualquier intento de pergeñar una "Teoría Universal del Derecho" de ámbito general y global -léase mundial-, por lo que nos vemos obligados a adoptar como paliativo teorías "regionales" del Derecho, como la que denominamos "teoría multidimensional islámica"61, eso sí, sin abusar de esta terminología, que no trasluce el fracaso y las limitaciones existentes a la hora de consensuar, si bien se adecúa perfectamente al ámbito bioético ${ }^{62}$. Las consecuencias jurídicas que de alguna manera convierten lo que debería ser un "principio universal" en un "principio estrictamente regional" se producen sobre todo a la hora de entender el art. 32 de la Declaración Universal de Derechos humanos de las NN.UU. ya que justo dicho texto prevé que "ninguna otra norma jurídica podrá derogar lo establecido en dicha declaración", lo cual es especialmente visible en el ámbito bioético en la medida en la que a partir del preciso momento en el que se ratifican y entran en vigor tratados o convenios sobre derechos humanos a nivel internacional ${ }^{63}$ (con su inherente e inescindible inter- 
pretación "laica" de las normas), ipso facto, por el principio de prelación de la ley internacional sobre la nacional, deberian ser éstos aplicados preferentemente a la legislación islámica de la Sharià, algo que evidentemente no se hace en el ámbito islámico, fundamentalmente en aplicación de las reservas ${ }^{64}$ especificas con las que se completan los susodichos documentos jurídico-vinculantes antes de ser sometidos a firma o a ratificación por parte de las autoridades competentes; no olvidemos, no obstante, que las reservas hechas por parte de los paises signatarios en los instrumentos internacionales correspondientes, en este caso en materias propias de convenios y pactos específicos sobre derechos humanos de cuño internacional, proceden y dimanan en último extremo de informes de los propios expertos islámicos, -léase de los jueces y magistrados islámicos-, extremo del que no suele quedar constancia reflejada en los propios instrumentos pero que cuando se conoce la dinámica de la especificidad o regionalidad del Derecho islámico subyace a todos ellos. En 2001 una de nuestras intervenciones públicas ad hoc fue: "Interpretaciones de la Ley Islámica: Seis variantes exegéticas actuales del Derecho Islámico contemporáneo", reseñada en El Diario de Sevilla con estas palabras: "La división del mundo árabe vino de la mano del jurista Mikunda quien estableció una clasificación que contenía seis modelos de Derecho que se aplican en el Mundo islámico"65. Dicho sea de paso, no se trataba ya por aquel entonces sino de constatar la realidad de la mencionada división, si bien no sólo del mundo árabe - como el desafortunado lapsus periodístico señalaba- sino de todo el orbe islámico66.

Y de nada sirve que se admita en dichos países islámicos como "principio de aplicación general" que en caso de colisión o conflicto entre derecho nacional e internacional se debe aplicar en primer lugar el internacional sobre el nacional o interno, a la hora de la verdad, y en la praxis jurídica, los textos internacionales son de hecho relegados a un segundo plano para evitar la incongruencia con los propios principios de la Ley islámica. En suma: una petitio principii. En todo caso resulta claro por la propia dinámica del Derecho islámico que no se admite ni se admitirá en el futuro acción jurídica alguna que abiertamente conculque el Derecho islámico regional esgrimiendo como único argumento su colisión con el derecho internacional, ya que la coherencia regional interna del sistema de fuentes jurídico-islámicas lo impide taxativamente; para ello habría que cambiar el propio ordenamiento jurídico-islámico de la Shari'à, lo cual es imposible dado su reenvío último a la voluntad de Dios reflejada en el texto dogmático revelado del Corán. Este tipo de tensiones únicamente desgarran y polarizan cada vez más a los propios destinatarios de las normativas constitucional e islámica, alli donde se dan ambas, abocados a conflictos de conciencia irresolubles, que incluso entre nosotros -si bien a otro nivel-, también parece que empiezan a despuntar ${ }^{67}$. Si se me permitiera el parangón diría que sería tanto como pretender cambiar un versículo de los evangelios cristianos, o de la Biblia, en caso de que su lectura discrepara del sentir social contemporáneo, -algo que igualmente resulta imposible a todas luces-, si bien en el caso de Occidente se puede acudir a la vía de la interpretación cultural-contextual para paliar el choque que pudiera producir la repulsa de los textos históricos ${ }^{68}$.

\section{1. Ética y bioética en el Mundo islámico $y$ en Occidente}

En el ámbito de la bioética se observa, por tanto, una tendencia similar a la acaecida respecto a la proliferación de textos de todo tipo, sedicentemente jurídicos, a nivel regional tanto en 0 ccidente ${ }^{69}$ como en el Mundo islámico ${ }^{70}$ del mismo modo al que ya se vino observando anteriormente en materia de declaraciones de derechos humanos a todos los posibles niveles ${ }^{71}$, cuando en modo alguno se limitó la polémica a la discusión entre la axiología jurídica de la "Declaración Universal de Derechos humanos"72 respecto de su inclusión en los valores occidentales o en los del otrora mundo del Este de Europa, sino sobre todo en torno a las diferentes concepciones de los derechos humanos islámicos dentro de la también múltiple paleta de ideas, instituciones y connotaciones que ostentan las escuelas jurídicas tradicionales de la Sharià junto con las asumidas por vía de la recepción del laicismo jurídico occidental, vía Qanún.

Por razones análogas a las aquí expuestas y como muestra inmejorable de la dimensión internacional que representan tales derechos, por razones análogas a las aquí expuestas y como muestra inmejorable de la dimensión internacional que representan tales derechos, creemos de obligada referencia señalar el discurso pronunciado ad hoc por Kofi Annan, Secretario General de las Naciones Unidas -consciente de las tensiones existentes entre ambos mundos, el islámico y el occidental- ante autoridades islamo-iranies para aclarar conceptos al respecto, en evitación de posibles 
malentendidos, de funestas consecuencias internacionales. "Los derechos humanos son el fundamento de la existencia y la coexistencia humana... La universalidad de los derechos humanos es lo que les da su fuerza. Les otorga el poder para cruzar cualquier frontera, escalar cualquiera muro, desafiar cualquier fuerza"73. Al día siguiente, ante la polvareda que tal discurso provocó, completó su visión sobre los Derechos humanos -facilitando a la vez la comprensión regional de los mismos ante sus auditores musulmanes- en una Conferencia de Prensa en la que mantuvo las siguientes tesis -tan discutidas como matizadas desde entonces a todo nivel posible- diciendo: "No existe un solo modelo de democracia, o de los derechos humanos, o de la expresión cultural para todo el mundo. Pero para todo el mundo, tiene que haber democracia, derechos humanos y una libre expresión cultural. Los derechos humanos son sus derechos. Tómenlos. Defiéndanlos. Promuévanlos. Entiéndanlos e insistan en ellos. Nútranlos y enriquézcanlos... Son lo mejor de nosotros. Denles vida. Cuando hablamos de los derechos humanos como un concepto de Occidente, ¿no llora la madre irani o la madre africana cuando su hijo o hija es torturada? ¿No todos sentimos cuando uno de nuestros líderes es injustamente encarcelado? ¿No todos sufrimos la falta del predominio de la ley y de la arbitrariedad? ¿Qué parte de esto es ajena? ¿Qué parte de esto es occidental? Y cuando hablamos del derecho al desarrollo; la necesidad de vivir la vida al máximo y de poder vivir sus sueños, eso es universal... Cuando hablan con individuos, ¿alguna vez han encontrado una víctima, alguien que haya sido torturado, que hable en contra de los derechos humanos? ¿Han escuchado la gente rechazar en general a los derechos humanos cuya intención es proteger a la misma gente? En todo lo que hacemos, sea desarrollo económico, seguridad, o lo que sea, hay un ser humano en el centro. $Y$ eso es lo que nosotros queremos decir cuando hablamos de derechos humanos, cuando hablamos de expresión cultural, de los derechos políticos y de los derechos económicos"74.

\subsection{Paralelismos con la problemática existente en torno a su inserción dentro de la categoría jurídico-filosófica "Derechos humanos"}

Ya vimos que al reconocer que no hay sólo un modelo de democracia, como mantiene el Alto mandatario de las NNUU antes citado, también puede reconocerse implícitamente de forma paralela la posibilidad de la existencia de otros modelos en otros ámbitos por ejemplo del Derecho y de los derechos humanos como son los regionales. La polémica sobre los derechos humanos que se había trasladado de la Declaración Universal de Derechos Humanos de 1948 en base al art. $30^{75}$ que excluye cualquier punto de vista regional, como el islámico por ejemplo, a las controvertidas Declaraciones de Derechos Islámicos ${ }^{76}$ de 1981, 1985, 1988, 1989, 1990, 1994 y sobre todo la de Teherán de 1997 y que finalmente lo ha hecho también a las Declaraciones Universales en materia de "Bioética y Derechos humanos". Así, el Prefacio de la "Declaración Universal sobre el Genoma Humano y los Derechos Humanos", aprobada el 11 de noviembre de 1997 por la Conferencia General en su 29. ${ }^{\text {a }}$ reunión por unanimidad y por aclamación, dice que "constituye el primer instrumento universal en el campo de la biología y que el mérito indiscutible de ese texto radica en el equilibrio que establece entre la garantía del respeto de los derechos y las libertades fundamentales, y la necesidad de garantizar la libertad de la investigación". A renglón seguido recuerda -mediante toda una batería de textos occidentales- "solemnemente su adhesión a los principios universales de los derechos humanos afirmados, en particular, en la Declaración Universal de Derechos Humanos de 1948 y Pactos Internacionales de Derechos Económicos, Sociales y Culturales, y Derechos Civiles y Políticos de 1966, la Convención de las Naciones Unidas para la Prevención y la Sanción del Delito de Genocidio del 9 de diciembre de 1948, la Convención Internacional de Eliminación de la Discriminación Racial de 1965, entre muchos otros, concluyendo en el art. 28 con una importante 'salvedad' en cuanto a la interpretación del mismo respecto de actos que vayan en contra de los derechos humanos, las libertades fundamentales y la dignidad humana" (que viene a ser un calco del art. 30 de la declaración Universal de Derechos Humanos de las NN.UU antes citada) ${ }^{77}$, que podría anular de un plumazo los efectos de los arts. 12 y 13 del propio texto, el primero de los cuales al predicar el respecto de la diversidad cultural y el pluralismo, y el segundo respecto de la solidaridad y cooperación internacional ${ }^{78}$. No podemos olvidar por tanto, en este contexto, que el citado mandatario de Naciones Unidas K. Annan declaró en 1997, con motivo de la Cumbre de Teherán -cumbre celebrada entre otros aspectos para debatir sobre temas de derechos humanos en el Mundo islámico- respecto del Islam: "Déjenme rendirle tributo a la gran fe y civilización del Islam. Ella ha ennoblecido y enriquecido a la humanidad a través de su historia. Hoy en día, inspira las creencias de más de mil millones de hombres y mujeres $y$ es una fuerza espiritual para la humanidad. Este hecho 
hace mucho más inquietante ser testigo del incremento en la violencia y el terror por grupos extremistas en el nombre del Islam. Están ensuciando la imagen de una religión cuyo nombre significa paz y cuyo Todopoderoso es el Compasivo y el Misericordioso"79.

Si observamos que una gran parte de las polémicas surgidas en Europa en el seno del Ilamado Estado de Derecho se han desarrollado entre nosotros, ciudadanos de la $U E$, en torno a dos conceptos claves que igualmente se proyectan en el ámbito de la bioética; primero, el relativo a la "tolerancia"80 - respecto de los Estados frente a las diferentes concepciones religiosas de todo tipo- $y$, segundo, el relativo a la "dignidad", esta vez respecto de las múltiples posibilidades exegéticas que conlleva el término aplicadas a la persona como tal, tanto por parte del ordenamiento jurídico como de las sociedades que lo soportan, ampliando sus efectos tanto a la vida antes de su concepción como en los momentos finales de la misma ${ }^{81}$, veremos que la tolerancia también aparece matizada en el Mundo islámico. Se constata especialmente en el ámbito jurisprudencial al otorgar la calificación jurídica de ciertas acciones como toleradas o admitidas (makró), en evitación de prohibiciones tajantes y categóricas, algo muy al uso en el espacio bioético en la llamada "vía de excepción", si bien hay situaciones que son de todo punto insostenibles en cualquier cultura: "Donde existe la esclavitud, es negada la dignidad humana, y avergüenza a todos los que dicen ser misericordiosos o comprometidos con los débiles y vulnerables del mundo. Los derechos humanos no son otra cosa sino la insistencia en la erradicación de la esclavitud y de la coerción en todos los aspectos de la vida. Pero aún así, en el umbral del nuevo milenio, seguimos encontrando formas viejas, y lamentablemente, nuevas de esclavitud. Miles de personas de todo el mundo viven y mueren como esclavos en una forma u otra"82. En Occidente una de las nuevas formas de esclavitud surgiría en torno al concepto bioético de "madres de alquiler" cuando la madre se decida a ello como un recurso desesperado para salir de la miseria, una forma de maternidad totalmente prohibida en el mundo islámico si no cumple los supuestos de vínculo matrimonial legítimo entre los donantes y la receptora.

Queda claro que históricamente surge una polémica en torno a la inserción de cuestiones bioéticas cristalizadas en torno a múltiples declaraciones locales y regionales en el seno de los Derechos Humanos, como fácilmente se constata, abiertamente incluso, en la Declaración de Bioética de Gijón de 2000, que comienza: "Considerando la Declaración Universal de Derechos Humanos de 1948, la Declaración Universal de la UNESCO sobre el Genoma Humano y los Derechos del Hombre del 11 de noviembre de 1997, la Convención de Asturias de los Derechos Humanos y la Biomedicina del Consejo de Europa del 4 de abril de 1997"83. Si a ello sumamos otro texto puntero universalista como la Declaración Universal sobre Bioética y Derechos Humanos de la UNESCO, París 2005, veremos cómo Occidente se divide entre el universalismo y el regionalismo, cuya evidencia realza el texto dimanante de la Declaración de Gijón al apoyarse a su vez en la sedicente "Declaración Universal sobre el Genoma humano y los derechos del hombre", uniendo indisolublemente cuestiones bioéticas con derechos humanos a un doble nivel universal y regional. Consecuentemente no hay que extrañarse que en el Mundo islámico la polémica en torno a la bioética se regionalice preferentemente, de acuerdo con su espíritu regionalista propio, en detrimento de presuntas universalizaciones lejanas en tiempo y espacio. Los ejemplos de los Códigos de Familia o Moudawannas son muy ilustrativos y complementarios en este sentido.

\section{Tensiones "internas" en el Mundo islámico}

\subsection{A nivel lingüístico: Glosario, panorámica terminológica básica, reflejo y sucinta muestra de la especificidad de connotaciones al uso en el ámbito interrelacionado de la Bioética, y la Jurisprudencia en los países islámicos hoy}

Al igual que ya constatamos la existencia de tensiones internas respecto de los Derechos humanos a la hora de su concreción en el Mundo islámico, al existir toda una batería de posibles interpretaciones derivadas del mero uso de las diferentes terminologías existentes ad hoc (en las que aquí no podemos entrar ahora, pero sí reenviar debidamente para su estudio) $)^{84}$ en el ámbito de la Bioética jurídica islámica, nos hallamos nuevamente ante un fenómeno similar, que incluso podría verse aumentado en el futuro en caso de que prosperen los movimientos feministas intra islámicos que pretenden, vía exégesis jurídica (ljtihad), introducir las perspectivas femeninas en los razonamientos jurídico coránicos. Mientras tanto, nos limitaremos a presentar las líneas lingüísticas básicas ac- 
tuales en torno a las que gira la exégesis bioética jurídica, tal y como se viene interpretando en nuestros días.

Por las susodichas razones adelantadas ya en la actual polémica en torno al multipolar feminismo islámico y en cómo se proyecta a través de las acciones bioéticas concretas de cuantas personas lo apoyan en el mundo real, es por lo que hemos seleccionado el elenco actual de términos lingüisticos al uso en la bioética genuina islámica dotados todos ellos de sus propias connotaciones, en los que predomina la nota de "trascendencia" -o reconducción en último extremo a la ética islámica primigenia basada en la Revelación divina- del Corán y demás fuentes complementarias (Hadices, consenso unánime de juristas islámicos, razonamiento individual, búsqueda del bien común o bien público -Maslaha-) para evitar el harto frecuente equívoco de dotarlos de connotaciones jurídicas exclusivamente occidentales ${ }^{85}$, -fundamentalmente de la nota de "inmanencia" que caracteriza como elemento común iusfilosófico básico a nivel comparatista toda concepción laicista del Derecho occidental- ${ }^{86}$.

Como podrá verse, en casi todos los términos del glosario, se añade la calificación islamo-jurídica, generalmente aceptada, de lícito (Halal) o ilícito (Haram) -léase prohibido o permitido-, o bien de rechazado (Haram) o tolerado (Makró) con la salvedad de la existencia de pensadores o corrientes disidentes ${ }^{87}$ que igualmente existen en el seno del común consenso ampliamente mayoritario logrado en el Mundo islámico mediante el recurso de celebrar jornadas y conferencias mundiales de juristas y/o expertos en Ciencias islámicas (Liga islámica mundial, Conferencia de doctores en Ciencias islámicas, etc.). El siguiente glosario presenta lo que consideramos la veintena de términos más elementales o básicos de cuño iusculturalista regional islámico que resultan a todo investigador no-musulmán la "clave" quizás más imprescindible para una correcta comprensión del fenómeno bioético y jurisprudencial al uso en el seno del fragmentado Mundo islámico contemporáneo. Al hacerlo así cumplimos el art. 15 de la Declaración de Bioética de Gijón 2000 cuyo fin básico es "armonizar y unificar conceptos mediante el estudio comparado de las connotaciones occidentales e islámicas propias de cada término empleado", toda vez que esta labor resulta indispensable para la comprensión intercultural y regional de los respectivos ámbitos jurídicos $^{88}$ (NB.: El glosario no se ordena por orden alfa- bético, sino reagrupando materias bioéticas vinculables, reenviando en las notas a pie de página a problemáticas similares en Occidente y/o España).

1. Fuentes jurídicas islámicas: Implican el Alcorán, la Sunna, las Ciencias del Hadiz, La Ley islámica o Shari'à (junto con los dictámenes -FATWAS- de sus cinco correspondientes Escuelas jurídicas consolidadas a las que indisociablemente van unidas, mostrando posturas incluso en algunos extremos totalmente discrepantes).

2. Clonación humana: Categóricamente prohibida como en Occidente ${ }^{89}$, en base a la nota de dignidad humana ${ }^{90}$.

3. Dignidad humana: subraya en el pensamiento jurídico-islámico el carácter sagrado de la persona humana como criatura individual de Dios ${ }^{91}$, añadiendo la dimensión "trascendental" a la puramente humana ${ }^{92}$, que tan sólo es inmanente ${ }^{93}$.

4. Entierro islámico: A efectuar en el mínimo plazo con prohibición explícita de incineración y/o cremación y mutilación de cadáveres ${ }^{94}$.

5. Vía de excepción: En caso de necesidad acuciante se autoriza hacer uso moderado de lo proscrito (carne de puerco, alcohol, drogas prohibidas, uso de insulina de cerdo en la diabetes). El uso y a veces abuso de esta vía jamás justifica ni deroga la prohibición subyacente, al ser de cuño religioso dogmático inderogable. Calificada de tolerable.

6. Perjuicios frente a terceros: Se evitarán en la medida de lo posible y en caso de necesidad se intentará que resulten mínimos ${ }^{95}$. Calificados de tolerables en casos puntuales y prohibidos en casos repetitivos evitables ${ }^{96}$.

7. Concepto islámico de enfermedad: Sólo Dios dispone de la salud y de la enfermedad. No existe enfermedad alguna sin remedio. A veces se desconoce -caso del Síndrome de inmunodeficiencia adquirida o SIDApero siempre existe ${ }^{97}$.

8. Deber de preservar la vida: Imperativo legal islámico con las salvedades exhaustivamente prescritas en la 
Sharià, en el apartado Derecho penal islámico ${ }^{98}(\mathrm{Hu}-$ dud), de aplicación restrictiva9 ${ }^{99}$. Las diferentes exégesis existentes ${ }^{100}$, producidas casuisticamente implican a veces el uso puntual de la vía de excepción ${ }^{101}$.

9. Muerte cerebral: Definida en 1986 en la Tercera Conferencia Internacional de Juristas islámicos (Jordania), como paro total e irreversible cardio-respiratorio, o bien como término de las funciones vitales del cerebro reflejadas en la destrucción del mismo, a juicio de facultativos médicos, independientemente de la posibilidad de mantenimiento artificial de la vida vegetativa a nivel de respiración y latido mediante máquinas ad hoc. En 1995 el Consejo de Jurisperitos islámicos del Reino Unido dictaminó que sólo los forenses están legitimados para definir la muerte en vistas a la donación de órganos. Su criterio se basa exclusivamente en cuatro signos inequivocos: 1. Pérdida total de la conciencia. 2. Falta total de respuesta biológico-funcional del cerebro, probada por: apnea, dilatación de pupilas, falta de reflejo en el iris, ausencia de respuesta frente al dolor intenso tras estímulo, no reacción tras introducción de catéter en la tráquea (excluye movimientos reflejos de automatismo medular). 3. Paro súbito de la respiración tras repetida desconexión de aparatos de ventilación mecánica, con falta de respuesta del paciente a la presión parcial del $\mathrm{CO}_{2}$ disuelto en la sangre, y 4 . Electroencefalograma: Debe ser en todo caso plano, repetido, de diez minutos de duración, y científicamente constatable a tres niveles: normal, doble y máximo ${ }^{102}$.

10. Autopsias: Disección de cadáveres. Lícita. Prohibición de mutilación incluso de cadáveres, salvo con fines de bien público (Maslaha), como el estudio anatómico, o la donación para transplantes.

11. Circuncisión: Lícita pero no obligatoria sólo en varones entre 4 y 14 años. Representa sólo un símbolo de pertenencia a la Comunidad islámica. Jamás es signo de Alianza con Dios, como en el Judaísmo.

12. Excisión femenina: Siempre prohibida implícitamente en países islámicos tradicionalistas. Prohibida categóricamente de forma explícita desde 1996 (Tantaoui) en todas sus formas y declarada "contraria a la tradición islámica"103.
13. Transplantes: El principio ético-jurídico básico de éstos es el altruismo ${ }^{104}$ : en base a una exhaustiva Fatwa sobre transplantes de 1988 dimanante de la Cuarta Conferencia de Juristas islámicos, de Yedda. 13.1 Transplante de piel, de vivo o de cadáveres: Lícitos desde 1973 (Gran Muftí de Egipto). En 1973 se amplió la casuistica incluyendo donantes anónimos, ya cadáveres. En 1982 y 1983 se ratificó en A. Saudita y Kuwait respectivamente. 13.2 Transplante de órgano donado generosamente por persona viva: Es lícito desde 1985 (Academia del Fiq islámico/Jurisprudencia de la Liga Islámica Mundial, de Meca) si ha sido consentido por el donante o por su familia con conocimiento previo del donante. 13.3 Transplante de órgano tomado de un cadáver en el musulmán: Es lícito si antes consintió el donante o si lo hace post mortem la familia, según la Escuela Hanbalí; es ilícito, según la Academia de Fiq Islámico de la India, puesto que el testador no puede disponer de su cuerpo, en calidad de usufructuario, cuerpo propiedad de Dios exclusivamente. 13.4 Transplante de órgano tomado de persona viva, en el musulmán: Es lícito y meritorio, salvo si interfiere en la propia vida del donante. 13.5 Transplante de órgano tomado de persona viva no musulmana: Es lícito sólo por vía de excepción, si no existen musulmanes donantes ${ }^{105}$. Es ilícito si media compraventa, salvo el caso de necesidad o vía de excepción, que lo hace admisible. 13.6 Transplante de córnea: Es lícito desde 1959 (Gran Muftí de Egipto). Ratificada 1988 en Yedda por el Gran Consejo de Ulemas hanbalies de Arabia Saudi. 13.7 Autorización testamentaria de donación de órganos: Es lícita con buenos fines ${ }^{106}$.

14. Compraventa de órganos: Es siempre ilícita incluso con buen fin. En casos de necesidad extrema es admisible para salvar vidas únicamente. Casuística de interpretación jurídica rigurosamente restrictiva.

15. Transplantes en embriones: 15.1. De tejidos procedentes de embriones ${ }^{107}$ y fetos ${ }^{108}$ (incluye la problemática de las células troncales ${ }^{109}$ ). Lícitos desde 1985 (Academia islámica del Fiq de La Meca), siempre con autorización de ambos padres, si bien se prohibe abortar sólo para procurárselos. Igualmente prohibido destruir una vida para restaurar otras ${ }^{110}$. 15.2. De gónadas: Categóricamente prohibido e ili- 
cito en cualquier caso, tratándose de testículos y ovarios, excepto si únicamente procuran hormonas al receptor. 15.3. Fetos sin encéfalo o anencefálicos: Permitida la investigación para resolver problemas terapéuticos a condición de no privarlos de vida anticipadamente. Por naturaleza fallecen al poco tiempo. Sólo son lícitamente manipulables post mortem. 15.4. Transfusiones: Permitidas, lícitas y recomendables como terapia y para salvar vidas; desde 1959 (Gran Muftí de Egipto) en base al bien público (Maslaha); permitidas incluso de no-musulmán a musulmán sólo en caso de necesidad extrema vía exceptionis; prohibidas en caso de ser el donante portador de enfermedades (SIDA, hepatitis, etc.).

16. Xenotransplantes: Son transplantes de partes o vísceras de animal sobre ser humano (corazón, páncreas, hígado) ${ }^{111}$. Permitido o rechazado según las escuelas islámicas, admitiéndose como solución transitoria 0 por vía de excepción incluso los xenotransplantes de partes del páncreas porcino, o del corazón o de sus válvulas. Tema muy discutido sobre todo por los peligros que encierra (Síndrome Kreuz-Feld-Jakob o de vacas locas), sin haberse llegado todavía a una conclusión unánimemente admitida.

17. Manipulaciones genéticas: 17.1. Diagnóstico prenatal: Lícito con consentimiento de ambos padres para evitar graves deformaciones (riñones poliquísticos, Corea de Huntington, etc.). 17.2. Huellas genéticas: Prohibida la difusión de ADN a terceros. Sólo permitidas frente a los padres legítimos, y a las autoridades judiciales como prueba de cargo y descargo a nivel penal exclusivamente ${ }^{112}$.

18. Contracepción o uso de anticonceptivos: Se permiten los anticonceptivos de todo tipo, incluso la píldora postcoital RU 486, por varias razones: salud, deterioro de la belleza de la esposa (p. ej. entre dos embarazos consecutivos sin pausa de recuperación), y por causas económicas, siempre que la autorice la esposa ${ }^{113}$. Se prohíbe expresamente su imposición, incluso por el Estado ${ }^{114}$, para limitar el número familiar de hijos o por razones demográficas ${ }^{115}$.

19. Esterilización: La esterilización definitiva (resección de trompas, vasectomía, p. ej.) puede ser ambiva- lentemente considerada como lícita o ilícita según los $\operatorname{casos}^{116}$. Está fundamentalmente recomendada para evitar enfermedades genéticas graves, o la realizada con fines terapéuticos por fuerza mayor y con conocimiento explícito y consciente del/de la paciente (casos de cáncer), o si el embarazo pondría en peligro de muerte a la madre. Se prohíbe como práctica de reducción demográfica y como vía experimental de técnicas médico-quirúrgicas nuevas o sin precedentes.

20. Procreación asistida: 20.1. Inseminación artificial: Sólo es lícita la del padre legítimo y vivo, en caso de infertilidad o esterilidad natural de alguno o de ambos progenitores. Se recomienda, ya que la adopción islámica está prohibida. 20.2. Fecundación in vitro: Se admite sólo la de los padres legítimos y para su vuelta al útero materno. Se prohíbe el uso de óvulos de terceras personas, así como de madres de alquiler, ni siquiera siendo parientes. Únicamente se practica lícitamente en óvulos cedidos ad hoc por futura madre musulmana, judia y cristiana, inseminados por esperma procedente de su esposo legítimo, según unos; según otros es ilícito aunque tolerable (Makró). La inseminación de terceros se asimila al adulterio, estando por tanto, categóricamente prohibida. La fecundación in vitro de óvulos de viuda con esperma congelado del marido legítimo es ilícita al no existir ya, por fallecimiento, el contrato matrimonial islámico bajo el que sólo es lícita la procreación. 20.3. La donación de embriones: Siempre prohibida, por proceder de terceros ajenos a los cónyuges legítimos. 20.4. Embriones excedentes: Pertenecen de por vida a los padres biológicos legítimos, mientras subsista el contrato matrimonial. Prohibida su comercialización incluso para fines benéficos, como por ejemplo ser reinsertados en el útero de mujer estéril. 20.5. Las madres uterinas no genéticas: Prohibidas radicalmente en todo caso, por no estar islámicamente vinculadas con el marido islámico contractual.

21. Los abortos: Salvo los espontáneos o naturales, todos los demás pueden ser lícitos o ilícitos según los casos. Los practicados por facultativos por error 0 los realizados sin motivo legal se castigan civilmente con el abono de una indemnización a los progenitores que equivale al décimo de la suma estipulada en caso 
de homicidio involuntario de musulmán. 21.1. Abortos de conveniencia o eugenésicos: Prohibidos si se practican para seleccionar el sexo, los genes, los caracteres psicofísicos del feto, o por comodidad para evitar molestias a los padres. Prohibidos incluso los trisómicos, ya que sólo Dios es dueño de la vida y de la muerte. 21.2. Abortos selectivos: Sólo permitidos en casos graves al peligrar la salud de la madre. (Se critica que Túnez, país islámico laico por definición, haya legalizado el aborto libre tras el tercer hijo o parto viable.) 21.3. Abortos para uso de tejidos en terceros: Prohibidos como regla general, permitidos en principio sólo en fetos declarados inviables y tras su certificación de muerte intra o extrauterina. Permitidos en fetos anencefálicos antes de la "animación" y sólo con fines terapéuticos en la persona de padres y hermanos genéticamente compatibles. El problema es que según las diferentes Escuelas jurídicas islámicas pueden considerarse lícito si se practican antes del día 20, o del 40, o del 80 o del 120 desde la fecundación, no existiendo consenso en este punto, por basarse únicamente en un Hadiz, reputado verdadero, de interpretación esencialmente pluralista en todos sus extremos ${ }^{117}$.

\subsection{Tensiones "internas" en el Mundo islámico entre las escuelas jurídicas oficiales}

Para comprender el alcance de los elementos existentes en bioética islámica y las tensiones internas a las que se ve sometida, nada mejor que consultar de primera mano la opinión de los propios pensadores musulmanes, especialmente de aquellos que ostentan cargos de especial relevancia y proyección sobre los colectivos de musulmanes existentes en Occidente (Europa, Continente americano y Australia sobre todo), toda vez que ellos se encuentran a la vez confrontados, no sólo frente a opiniones divergentes y disidentes del propio colectivo, sino sobre todo frente a las corrientes de opinión propias de la Unión Europea. De este modo, consultado uno de los más claros y asequibles exponentes del pensamiento bioético islámico sunní, Dalil Boubaker, Rector del Instituto islámico de la Mezquita de París, hallamos que en internet presenta todo un amplísimo elenco de cuestiones tanto religiosas como bioéticas presentadas en su doble perspectiva islámico-científica. En todas ellas, sin excepción, parte de la base primigenia del estudio de las posibles fuentes clásicas islámicas (Corán,
Sunna, etc.) para remontarse, sea por analogía (Qiyás), sea usando el propio razonamiento (Ra'i). Así se evidencia meridianamente v.gr. en su exposición sobre "diagnóstico prenatal"118.

Otro autor, no menos reputado (especialmente por sus esfuerzos por intentar hacer comprensible a sus colegas occidentales los puntos de vista bioéticos de cuño islámico), afincado igualmente en Europa (Alemania), el Dr. IIjan Ilkilic, del "Centro de investigación de la ética en las Ciencias de la Universidad de Tubinga", bajo la dirección del catedrático Hass-Martin Sass, no sólo advierte del actual e intenso debate intraislámico, sino incluso recuerda que "la clave del mismo se reconduce a las diversas teorías existentes en el Mundo islámico sobre el 'momento justo' en el que se produce la entrada del alma en el embrión humano", ya que existen dos opiniones encontradas e irreconciliables en el Mundo islámico contemporáneo que, al dar pie a dos corrientes de pensamiento distintas, ponen de manifiesto que dicho "momento" es un aspecto temporal básico insoslayable para definir bioéticamente el nivel de protección jurídica del embrión y, por ende, del ser humano como tal ${ }^{119}$. Las consecuencias e implicaciones a la hora de decidirse cada pensador por una u otra tesitura no son en modo alguno ociosas ni bizantinas, ya que complican a nivel bioético en caso de decidirse, cualquiera de ellas, consecuencias juridicas irreversibles. De este modo, si la decisión es por la primera tesis, a saber, que "el momento justo de la entrada del alma o animación transforma el status jurídico del embrión categóricamente, pasando a partir de entonces a ser 'persona humana"; o por la segunda, que mantiene que "el embrión se convierte progresivamente en persona humana", implica que en el primer caso podrían usarse anticonceptivos tales como la píldora RU 486 postcoital e incluso ejercerse manipulaciones biogenéticas lícitas sobre el embrión "antes" del momento justo de animación, pero jamás "después", por su transformación instantánea en persona humana; mientras que en la segunda al ser una transformación progresiva desde el momento mismo de la fecundación, imposible de detectar con medios humanos, quedaría excluido, no sólo todo tipo de anticonceptivos postcoitales, sino incluso todo tipo de manipulación bioética o genética en el embrión, al resultar imposible de conocer a ciencia cierta el momento justo de su transformación en persona humana, por miedo a cometer posibles errores de apreciación. Respecto de la primera tesis hay que indicar que una de sus 
consecuencias lógicas implica un agravante añadido, como es saber el "momento justo de animación", dificultad que ya produjo una polémica multisecular desde el s. VIII en todo el Mundo islámico dando como resultado toda una paleta de opiniones dispares al efecto, a tenor de las cuales éste puede producirse sea en 40, sea en 80 o incluso en 120 días desde el momento de la fecundación -dependiendo de la exégesis de cada Escuela jurídica islámica- factor que no ayuda especialmente a resolver los problemas planteados a nivel teórico, pero que sirve como justificación en muchos casos para proceder a practicar intervenciones biogenéticas en la praxis médica cotidiana, dependiendo del grado de concienciación personal de padres y personal sanitario. Otro autor musulmán, especialista en genética, el Dr. Imran Siddiqi argumenta no sólo haciéndose eco ante todo de la Ley islámica clásica (Shariah) respecto de sus distinciones entre vida en acto y vida en potencia, de cuño eminentemente aristotélico, sino que las aplica consecuentemente al espinoso tema del destino de los "embriones excedentes" alegando que "si realmente se tratara a los embriones como seres humanos de pleno derecho, ni se producirian excedentes que necesariamente habria que destruir posteriormente, destruyendo así a tales seres humanos"120. He ahí-según él- la prueba suprema de que nadie los trata ni toma en serio como seres humanos en la realidad, -y concluye- añadiendo que discrepa de la postura oficial de la Iglesia Católica ${ }^{121}$, cuando mantiene que destruir los embriones excedentes es el equivalente a practicar un infanticidio.

Desde el punto de vista chiíta hallamos igualmente perspectivas interesantes. El Ayatola Sayyed M. Hussein Fadlallah es un experto en temas bioéticos islámicos, aparte de ser condiderado un autor extraordinariamente liberal en el seno del pensamiento islámico por la experta Gisèle Eid ${ }^{122}$, con cuya visión no necesariamente coincidimos, toda vez que admite que la clonación humana "no puede calificarse a priori de buena o mala antes de saber cuáles son sus resultados"123, mostrando un talante consecuencialista difícil de casar con la ética clásica islámica basada en puros principios. Boustany, sin embargo, tiene muy claro que la clonación en todo caso es rechazable, en base a reflexiones dimanantes no sólo de la naturaleza humana sino del puro acto físico de la procreación humana, en el que "un hombre y una mujer contribuyen en conjunto a engendrar una persona de características imprevisibles e irreductibles única y exclusivamente a la de sus progenitores, que no es sino el reconocimiento de su singularidad y autonomía, ambos elementos esenciales de la dignidad de la condición humana"124.

En otro orden de cosas, como el de los problemas planteados por la eutanasia en todas sus formas, el experto islamista Hamza Boubaker llama la atención al estudioso de temas de bioética comparada no sólo por el hecho de remitirse en sus análisis a otros colegas islamistas, de los que reproduce sus argumentos adhiriéndose expressis verbis a ellos, sino sobre todo por aludir casi exclusivamente en apoyo de sus tesis a pensadores mayormente cristianos occidentales, desde Bacon a los averroístas, tomistas, cartesianos etc., a la hora de fundamentar una Fatwa (dictamen jurídico islámico) de su autoría a uso de los creyentes en materia de eutanasia ${ }^{125}$. En cambio, ciertos pensadores occidentales, que en base a sus reflexiones nos inducen a creer que se trata quizás de curiosos dedicados al estudio de fenómenos con implicaciones bioéticas en el mundo islámico, juzgan quizás muy precipitadamente y sin suficientes elementos de juicio -amparándose en el anonimato de internet- ciertas opiniones islámicas por ejemplo en materia de derechos del feto o nasciturus, interpretando que: "Los derechos del feto se basan 'en el hecho' de que al no estar suficientemente formado el sistema nervioso no puede hablarse todavía de ser humano; a fortiori respecto del embrión, del óvulo o del espermatozoide"126, cuando en realidad la clave se halla en la doctrina jurídica islámica de la animación según la Schari'à, no en el hecho de la formación del sistema nervioso.

Está claro, que desde hace tiempo, nos hallamos todos inmersos en un enorme caos, no sólo biomédico, sino ético y jurídico, realidad que se evidencia especialmente en materias de bioética, por ser lugar común donde en vez de resolverse las cuestiones ya planteadas lo único que se consigue es multiplicarlas ad infinitum debido al surgimiento via feed-back o retroalimentación de nuevas experiencias técnico-científicas ( $y$ de posturas éticas) que obligan a replantearse todo lo ya andado de nuevo ${ }^{127}$.

\subsection{En los actuales "movimientos feministas" emergentes en el Mundo islámico}

Hoy en día las tensiones empero no nacen ya solamente de las connotaciones lingüísticas de los términos usados en el tráfico estrictamente jurídico, sino en el de la vida co- 
tidiana de las grandes urbes en donde nos hallamos todos, hombre y mujeres por igual. Por esta razón constatamos que es la tensión por lograr una equiparación -más que una igualdad- entre los sexos el elemento que figura en primera línea en sus aspectos más reivindicativos, y ello tanto en Occidente como en el Mundo islámico. K. Annan es categórico al respecto: "Que no quepa duda; existen algunas normas muy básicas de comportamiento humano, las cuales no aceptan violación. Los derechos humanos fundamentales son un producto de la naturaleza humana en sí $-y$ de hecho de la vida humana misma-"128.

El feminismo occidental (o sus variantes, los feminismos occidentales) ${ }^{129}$ y el feminismo islámico (del que también existen numerosas variantes) dan fe del pluralismo políticocultural que nos circunda como fenómeno bien visible propio de nuestro siglo. La tensión que genera el epifenómeno del feminismo a múltiples niveles ha sido condensada en textos tan señeros como el siguiente: "La emergencia del feminismo islámico nos remite al reconocimiento de una realidad plural. El feminismo no es un movimiento monolítico, sino una serie de propuestas tendentes a la consecución de la igualdad de sexos, que se enraiza en la historia concreta de las mujeres y adopta diferentes expresiones según las condiciones. En palabras de Mary Nash, autora de 'Mujeres en el mundo', el feminismo no puede ser reducido a una filosofía o a una metafísica. Desde una perspectiva histórica, queda claro que los entornos culturales, sociales, políticos o religiosos han afectado y afectan al desarrollo de la teoría feminista y han influido de forma decisiva en la propia forma de interpretar el feminismo"130. Quizás por ello reconoce el articulista que de todas las definiciones que él conoce, tal vez la más precisa sea la de Margot Badran al definir "feminismo islámico" calificándolo de "un discurso y una práctica feminista articulada dentro de un paradigma islámico. El feminismo islámico, que deriva su comprensión y mandato del Corán, persigue derechos y justicia para las mujeres y para los hombres, en la totalidad de su existencia"131.

Vemos por tanto como la problemática en torno a las definiciones ha llegado incluso a teñir lo que parecería más ajeno a las mismas, pues de entrada es evidente que por feminismo islámico se debería entender el tipo o tipos de feminismo que se practica en el mundo islámico, sin más; sin embargo el adjetivo "islámico" añadido a feminismo no debería implicar una reducción de la exigencia básica de la igualdad de sexos, en su sentido más universal, pese a ha-
Ilarse en un contexto cultural jurídico-regional. De ahí que Shirín Ebadi premio Nóbel de la Paz mantenga por su parte -aclarando conceptos y definiciones- que: "Si el feminismo islámico significa que una mujer musulmana puede también ser una feminista y que feminismo e islam no son incompatibles, estaría de acuerdo con ello. Pero si significa que el feminismo en las sociedades musulmanas es algo peculiar y totalmente diferente al feminismo de otras sociedades por el hecho de que tiene que ser siempre islámico, entonces no estoy de acuerdo con semejante concepto"132.

\section{Tensiones "externas" existentes en materia de BioÉtica en el Mundo islámico, frente a OCCIDENTE Y FRENTE A OTRAS CULTURAS JURIDICAS DE CUÑO NO-OCCIDENTAL}

Finalmente podemos constatar que el Mundo islámico actúa frente a Occidente a nivel de reflexión bioética en base a "diferentes parámetros exegéticos" respecto de los textos religiosos que podríamos considerar comunes ${ }^{133}$ (Dios, el rol del ser humano en y tras la creación, etc.), todo lo que nos lleva a su inclusión como fenómeno iuscultural regional desde una perspectiva de estudio jurídico-filosófico del Derecho, alejado por tanto del parámetro "universal" propio de concepciones y de teorías de cuño occidental ${ }^{134}$. De este modo no sólo es constatable la mera existencia de una regla básica que podría ser enunciada asi: "El interés en cuestiones bioéticas que se produce en cada país o Estado islámico es directamente proporcional al nivel económico o renta per cápita de sus ciudadanos", con lo que cuanto más pobre sea el país analizado tanto menos recursos podrá desviar para cuestiones bioéticas de este tipo y consiguientemente tanto menos interés mostrará en este tipo de cuestiones, y viceversa; cuanto más rico sea, tanto más dinero dedicará a subvencionar instituciones e investigadores relacionados con ellas. Ahora bien, más allá de esta consideración estrictamente economicista, donde realmente aparecen divergencias interpretativas es a la hora de interpretar temas como "el rol divino" (La creación bíblica se considera perfecta y acabada el séptimo día, mientras que el relato coránico la considera proceso permanente in fieri); el "papel del ser humano al manipular genéticamente embriones para clonarlos o células humanas" considerado en el cristianismo un dislate al pretender asimilarse a Dios mismo en la creación, mientras que para el Islam tan sólo 
representa un mero reflejo del poder divino del que el ser humano reproduce una ínfima parte, permitida por Dios en todo caso, incluso en el acto de posibles clonaciones humanas $^{135}$. Como podemos constatar, en este ámbito es ya de entrada muy difícil de alcanzar un consenso transcultural, por la disparidad de posiciones de partida. Ahora bien, no sólo se da frente a Occidente. Como dato complementario útil para una comparatística de amplio espectro destacamos el hecho de que en otros países del mundo y por encima de presuntas "consideraciones políticas" de sus autores - como se suele siempre escuchar en sordina- realmente es la respectiva concepción religiosa dominante en personas y colectivos bien definidos el factor que decide sobre la licitud o ilicitud de intervenciones clínicas relacionadas con asuntos bioéticos, más allá de fuentes político-jurídicas oficiales, al remitirse en último extremo a la libertad de conciencia tanto de quienes las ponen en práctica como profesionales, como de los sujetos que consienten en que se les practiquen; en este sentido nos limitamos a exponer sólo tres ejemplos: 1. Que es en Israel donde el representante del Judaísmo oficial es considerado ultraliberal a nivel de cuestiones bioéticas, toda vez que "según la opinión del judaísmo la vida únicamente comienza en el momento justo del alumbramiento, razón por la cual se permite toda investigación con embriones humanos en espera de que las ventajas superen los inconvenientes de la misma"136. 2. Que en ciertos países budistas, como Nepal, pese a considerarse la vida un "continuo proceso de reencarnaciones" se rechaza no obstante la investigación embrionaria por ser considerada como un atentado contra el principio éticobudista que ordena "abstenerse de hacer uso de violencia alguna" (en este caso "con alevosía contra el embrión"); y 3. Que en la India, el hinduismo oficial actúa a un doble nivel contradictorio; por un lado se considera que la vida humana surge en el momento mismo de la fecundación o concepción $y$, por otra, se permite la investigación con embriones durante los primeros catorce días desde ésta por razones terapéuticas ${ }^{137}$. La polémica está pues servida durante décadas ${ }^{138}$.

\section{ONCE TESIS COMO CONCLUSIONES SIEMPRE PROVISIONALES}

1. La polémica de antaño en torno a la universalización o regionalización de los derechos humanos desde la óptica específica del Derecho islámico contemporáneo en su vertiente concreta de los llamados "Derechos humanos islámicos", tanto en su vertiente laica como en la netamente islámica tradicional cristaliza a favor de decantarse claramente como regional al mantener la vinculación de los derechos humanos islámicos sensu stricto sólo frente a los creyentes musulmanes, aplicándose por analogía sensu lato a los no creyentes.

2. El Mundo islámico se halla dividido a nivel de reflexión y práctica bioético-jurídica en los mismos ámbitos, sunní y chií, que el islámico clásico. De ahí que en el sunnismo se den diferentes opiniones, incluso opuestas en materias bioéticas similares, al carecer de instituciones individuales y personales basadas en el principio de autoridad religioso-dogmática, mientras que en el chiísmo la coherencia es mucho mayor por disponer de líderes religiosos visibles en materia de dogmas religiosos. Es una de las fuentes de tensiones más relevantes que van acentuándose a lo largo del tiempo.

3. La bioética jurídica islámica permite toda técnica de procreación asistida a condición de respetar escrupulosamente la filiación genética de ambos progenitores o padres. Consecuentemente tanto el espermatozoide como el óvulo deben proceder sólo y exclusivamente de padres biológicos jurídicamente legítimos, es decir, unidos en vínculo matrimonial, excluyéndose tanto en caso de divorcio, como en el de fallecimiento marital cuando existe semen congelado potencialmente capaz de fecundar óvulos (de la viuda únicamente).

4. El embrión se considera persona a partir del momento de su "animación" (o entrada del alma en el mismo), discrepándose del "momento exacto" según las escuelas jurídicas islámicas oficiales, existiendo por ello amplias variaciones que van desde el mismo día de la fecundación, como en el cristianismo, hasta ciento veinte días después, según la Escuela jurídicoexegética islámica de referencia.

5. Las manipulaciones genéticas están fundamentalmente prohibidas si versan sobre el sexo, el genoma, sus potencialidades y fines propios. Como terapia serían lícitas o, cuando menos admisibles, salvo cuando impliquen destrucción de una vida. 
6. Toda manipulación bioética del cuerpo humano, transplantes, transfusiones, intervenciones clínicas, diagnósticos etc., se rigen por el principio islámico de "conservación de la vida humana, de su respeto, cuidado, salvaguarda de su estatuto de dignidad personal humana, en vida y en la muerte", así como por el del "respeto de su voluntad en caso de fallecimiento o in articulo mortis", siempre de acuerdo con las enseñanzas religiosas del Islam a través de la exégesis practicada por las Escuelas oficiales de la Ley Islámica en sus diferentes versiones.

7. La globalización, como fenómeno, ha producido indirectamente el epifenómeno de toma de conciencia masiva de temas bioéticos en el Mundo islámico reflejados no sólo a través de las fuentes clásicas oficiales de Jurisprudencia, sino (vía ijtihad) a través de la exégesis privada o de opinión que se realiza en los foros de internet por pensadores, intelectuales y no intelectuales islámicos, que influyen en colectivos de musulmanes a nivel particular, ajenos a las vías y formas oficiales de expresión, pese a estar desaconsejado su uso por los expertos. El fenómeno es claramente constatable en los colectivos feministas islámicos via Internet, fenómeno acusado in crescendo.

8. El alcance de los elementos existentes en bioética islámica se percibe, desde la perspectiva de los propios juristas musulmanes, de hecho, como una bioética regional, si bien con "pretensiones universalistas" en la medida en la que esperan que toda la humanidad, algún día, se convierta, si es la voluntad de Dios, al Islam como religión subyacente a la susodicha bioética.

9. El valor que se atribuye en el Mundo islámico a la Declaración Universal sobre "Bioética y Derechos Humanos" de 2005 o a cualquier otra similar de cuño netamente occidental y sedicentemente universalista en su enunciado es similar a la que se atribuye a cualesquiera otras declaraciones de tipo regional ${ }^{139}$ sien-

Recibido: 24 de noviembre de 2008

Aceptado: 15 de diciembre de 2008 do admitidas o rechazadas únicamente en función de su adecuación material a los enunciados de la Ley Islámica o Shari'à, independientemente de su status formal dentro de la escala de prelación jurídica de las fuentes del Derecho Internacional.

10. Las fuentes de conocimiento en materia de bioética islámica no sólo se reconducen a las opiniones de expertos en cada una de las materias sobre las que versan, sino que igualmente llevan implícitos los principios intersubjetivos de la ética islámica de las respectivas escuelas jurídicas que pueden también manifestarse a través de dictámenes jurídicos (Fatwas) que si bien -en puridad de conceptos-, "teóricamente sólo vinculan en conciencia", de hecho dependerá de la voluntad de cada uno de los Estados islámicos el grado de efectividad real de los mismos al estar subordinados administrativa y públicamente al ordenamiento jurídico vía Constitución o vía Qanún.

11. En los ámbitos de investigación respecto de "materias propias de bioética islámica" resulta absolutamente imprescindible la consulta de opiniones, no sólo de expertos occidentales, sino sobre todo, se debe estimar de primera mano las de los propios expertos y pensadores musulmanes -tanto sunnies como schiíes- por una doble razón que se da simultáneamente: ratione loci et materiae; en especial las de todos aquellos que ostentan cargos de especial relevancia y proyección sobre los colectivos musulmanes existentes en Occidente (Europa, Continente Americano y Australia principalmente), como vgr. directores de Centros de Enseñanza Superior, Mufties, juristas y magistrados, profesores y catedráticos tanto islámicos como laicos, médicos y especialistas biomédicos islámicos, etc., toda vez que éstos se encuentran confrontados, no sólo frente a opiniones divergentes procedentes de tradicionalistas y disidentes del propio colectivo musulmán en el que viven, sino sobre todo por ser conocedores de las posturas dimanantes de las corrientes de opinión propias de la UE y del Mundo anglosajón. 
1 Prof. tit. de Filosofía del Derecho en la Universidad de Sevilla. Ha editado en 2003 la 1. reimpresión de su obra Derechos Humanos y Mundo islámico, varias veces recensada: La 1. ${ }^{\circ}$ del Prof. A. Osuna, en Rev. Estudios Filosóficos, n. 150 (2003) pp. 423424); la 2. ${ }^{a}$ en A.F.D., Nueva Época, tomo XX (2003), pp. 375-378; la 3. ${ }^{a}$, muy amplia de C. Pereira Porto, en Anales de la Cátedra Francisco Suárez, 36 (2002), pp. 373-382 bajo: Bases para un diálogo intercultural sobre Derechos humanos, calificada de obra imprescindible para entender las claves del Derecho islámico actual desde la perspectiva específica de la filosofía juridica, con especial referencia a los conflictos básicos que se plantean entre las diferentes concepciones islámicas y las concepciones occidentales a propósito de la interpretación de derechos humanos y fundamentales, por lo que constituiría un texto clave para entender los trasfondos jurídicos islámicos que subyacen a los sucesos del 11-S en Nueva York y 11-M en Madrid - a los que se anticipa- a través de la tipificación de seis clases distintas de exégesis sobre el valor atribuible a la Sharià o Ley islámica por parte de los estudiosos del Derecho vigente en países del Mundo islámico. Posteriormente se completa -como segunda parte de una trilogía- mediante un estudio publicado en alemán "Gemeinislamisches Verfassungsrecht. Eine Untersuchung der Verfassungstexte islamischer Staaten in rechtsphilosophisch vergleichender Perspektive", en J. Ö. R., Nr. 51, pp. 51-79 (2003), recensado por Prof. Dr. Albrecht Weber (Universidad Osnabrück/RFA), en Buchbesprechungen, 21/2004, Heft 21, p. 1353 (Dt. Verwaltungsblatt, Carl Heymannsverlag, 2004), constatando que relaciona textos jurídico-constitucionales existentes en países confesionalmente islámicos, en todo o en parte, buscando los posibles elementos comunes que presentan entre sí, tras reagrupar las materias de estudio en grupos de paises islámicos novedosamente según "afinidades lingüísticas y escuelas exegéticas jurídico-islámicas", en línea con su anterior trabajo "Der Verfassungsstaat in der islamischen Welt", pp. 151-153, publicado dos años antes en $\mathrm{Ba}$ den-Baden como capítulo del libro Crestomatía, col. Die Welt des Verfassungsstaates (M. Morlok, coord.), Nomos Verlagsgesellschaft, BadenBaden, (2001), recensado en inglés por Florian Hoffmann en 4 German Law Journal, n. ${ }^{\circ}$ 1, 01 january 2003, Legal Cultural Book Review Häberle and the World of the Constitutional State, pp. 61-69.

2 Ruiz de la Cuesta, Antonio (coord.): Ética de la vida y la salud. Su problemática biojurídica, edit. Secretariado de Publicaciones de la Universidad de Sevilla, 2008, ISBN: 978-84-4721116-6.

3 Fernández Segado, Francisco (coord.): Dignidad de la persona, Derechos fundamentales, Justicia constitucional y otros Estudios de Derecho Público, edit. Dykinson, Madrid, 2008, 1.209 pp.

4 Alemania, Austria, Brasil, España, Francia, Italia, Perú, Polonia, Portugal, Reino Unido, Rumania, Suiza y Venezuela.

5 "Los derechos humanos son universales, indivisibles e interdependientes ... La universalidad de los derechos humanos es lo que les da su fuerza".
Extracto del Discurso de Kofi Annan en la Universidad de Teherán en el Día de los Derechos Humanos, 10 de diciembre de 1997. Fuente doc. SG/ SM/6419.

6 Kofi Annan en 1988 insistía: "Debemos reafirmar la Declaración Universal de los Derechos Humanos y hacer que el público entienda, que el individuo entienda, que esos derechos le pertenecen. No es algo que el gobierno brinde, como un subsidio que pueda ser retirado. Es intrínseca, es inherente, y (espero) que podamos realmente utilizar este cincuentenario para difundir ese mensaje". Conferencia de Prensa en la sede de la ONU después de informar al Consejo de Seguridad sobre el Memorando de Entendimiento firmado en Bagdad, 24 de febrero, 1998, en SG/SM/6470.

7 Perez-Luño, Antonio Enrique (1998): "La universalidad de los Derechos humanos", AFD. Nueva Época, tomo XV, pp. 97-110; posteriormente reelaborado e incluido como cap. 6 en: La tercera generación de derechos humanos, edit. Thomson, Aranzadi, 2006.

8 Y hasta se diserta sobre el "deber universal del cuidado" referido a médicos. En Ética de la vida y la salud, cit., cap. X, pp. 175 y ss.

9 Vid. Mikunda Franco, E.: Derechos humanos y Mundo islámico, publicaciones de la Universidad de Sevilla, 2001, 1. a reimpr. diciembre 2003, esp. su "Apéndice documental", pp. 213 y ss.

100 quizás algo más peyorativo como "Concepciones sociologistas del Derecho", vid. Perez-Luño, A. E., Teoría

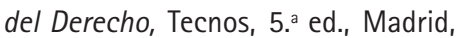
2007, cap. 6, pp. 87-104.

11 Mikunda Franco, E.: "I diritti umani come fenomeno culturale regionale", 
en Scienza \& Politica, n. ${ }^{\circ}$ 29, 2003, edit. Clueb, Bolonia (Italia), pp. 4765.

12 Mikunda-Franco, E.:"Diritto costituzionale comune islamico. Un'indagine comparata sui testi costituzionali di alcuni Stati islamici", en Tradizioni culturali, sistemi giuridici e diritti umani nell'area del mediterraneo, Colombo V., Gozzi G. (a cura di), col. Democrazie, Diritti, Costituzioni, edit. II Mulino, (2004). ISBN: 88-15-096566 ; pp. 261-288. (Recensado por Nicola Fiorita, Universidad de Bolonia, en Rev. I/ Diritto ecclesiastico, Anno CXV, fasc. 1, 2004, pp. 182-185.)

13 Mikunda Franco, E.: Filosofia y Teoria del Derecho, en P. Häberle (edit.), Dykinson, Madrid, serie D. ${ }^{\circ}$ Constitucional. Prólogo de P. Häberle. Nota de Fco. Fernández Segado (en prensa, febrero 2009).

14 "El capítulo 4 lo dedica al norte de África, relación Islam-Derechos Humanos. Kabunda manifiesta cómo aquí la realidad está colonizada por la religión. La referencia religiosa rige el comportamiento político y la ley coránica se convierte en la vara por la que todo se mide. Sin embargo, se interpretan de forma interesada por quienes controlan el poder de ese Estado-Religión que ellos mismos han instaurado. "Estas capas dominantes oscilan entre los valores adquiridos de Occidente y unos valores tradicionales que no controlan ni asumen plenamente. Ello revela la incapacidad de los dirigentes musulmanes para crear una cultura que vele por sus intereses y por los del substrato más hondo de su sociedad. Ésta es una de las causas de la 'occidentalitis' que afecta a la mayor parte de los musulmanes y que hace que se difunda el islamismo como reacción oportuna, bus- cando el reequilibrio". Recensión de Marina Blanco Nieto. ISEL del libro de Mbuyi Kabunda Badi, Derechos Humanos en África. Teoría y Práctica, Bilbao, Universidad de Deusto, 2000. http://www.isel.org/cuadernos_S/ Varios/m_blanco. Htm.

15 P. Häberle: "La dignidad como fundamento de la Comunidad Estatal", en Fernández Segado, Francisco (coord.), Dignidad de la persona, Derechos fundamentales, Justicia Constitucional, cit., pp. 173-237.

16 Op. cit., pp. 228-232. Esp. p. 235.

17 Art. 1 Grundgesetz der Bundesrepublik Deutschland: Die Würde des Menschen ist unantastbar.

18 Mikunda Franco, E.: "La proyección del libro 'Derechos humanos y Mundo islámico' visto en retrospectiva desde el 11-S. Un comentario de su autor y su impacto en Europa", en Actas de la Fundación Tres Culturas del Mediterráneo, Sevilla, 2007-2008.

19 Original alemán de 2003: "Gemeinislamisches Verfassungsrecht. Eine Untersuchung der Verfassungs-texte islamischer Staaten in rechtsphilosophisch vergleichender Perspektive", recensión igualmente en alemán a cargo del Prof. Dr. Albrecht Weber (Universität Osnabrück), en Buchbesprechungen, 21/2004, Heft 21, Seite 1353 (dt. Verwaltungsblatt, C. Heymannsverlag, 2004).

20 Diritto costituzionale comune islamico. Un'indagine comparata sui testi costituzionali di alcuni Stati islamici, vid. nota 12 ut supra.

21 Mikunda Franco, E.: "I diritti umani come fenomeno culturale regionale", en Scienza \&t Politica, n. ${ }^{\circ} 29,2003$, edit. Clueb, Bolonia (Italia), pp. 4765 passim.

22 Mikunda Franco, E.: "Peter Häberle en calidad de iusfilósofo pionero del constitucionalismo europeo", en rev.
Cuestiones constitucionales, RMDC (2006), pp. 193-221.

23 Mikunda Franco, E.: "Die Debatte um die Europäische Verfassung aus spanischer Sicht", en Eine Verfassung für die Europäische Union. Beiträge zu einer grundsätzlichen und aktuellen Diskussion, H. Timmermann (Hrgb.), edit. Leske+Budrich, Opladen, Alemania (2001), pp. 199-214.

24 En este sentido, coincidiendo igualmente: W. AA.: Kulturübergreidende Bioethik. Vorasussetzungen, Chancen, Probleme, DFG, 2002, (Déclaration on Human Genome and Human Rights, 1997), p. 3.

25 Eich, Th.; Breifeld, H.: Bioethik im christlich-islamisch Dialog (KonradAdenauer-Stift.), pp. 55-67.

26 En este sentido, igualmente el experto libanés en bioética islámica, el Prof. Fouad N. Boustany, Secretario Gral. del Comité Consultivo Nacional libanés, señala: "Cette réflexion, théorique et pratique concerne non seulement lers scientifiques, mais aussi toutes les composants de la société: Philosophes,sociologues, hommes de réligion, juristes et pouvoir politique", en La Bioéthique: Définition et legislation (vid. bibliografia in fine: http://fm.usj. edu.lb/anciens/ biolegi.htm).

27 La noticia siguiente está falta, todavía, de confirmación pero indica de hecho las tensiones existentes entre los colectivos de mujeres respecto a, p. ej., la transmisión del derecho a la nacionalidad a sus hijos. Vía Qanún: "La possibilité pour une femme marocaine de transmettre sa nationalité à ses enfants n'est pas reconnue dans la Moudawana, mais après un campagne publique est recueillie dans le nouveau code de nationalité, le roi Mohammed VI l'a autorisé en octobre 2006; la loi 
a été approuve au Parlement. [Code de Nationalité Marocain]". Extracto de prensa marroquí en Wikipedia,en francés, oct. 2006.

28 Vgr. actualmente en Marruecos, a la sazón envuelto en una viva polémica tanto confesional interna malequi como política respecto de la exégesis del denominado "Código de la Familia", del 5 de febrero de 2004, que sustituye al anterior de 1957, en un polémico intento de armonizar el pensamiento islámico con la modernidad y los Derechos humanos, entendidos éstos según la exégesis realizada por juristas marroquies oficiales. Vid. "Code de la Famille", publications de l'Association de I'Information Juridique et Judiciaire (A.D.I.J.J.), col. Textes Legislatifs, n. 9 , 1. a ed., octobre 2005.

29 Kulturübergreifende Bioethik, Voraussetzungen, Chancen, Probleme (Projektziele, p. 3), op. cit., i.f.

30 En el sentido explicitado por A. E. Pérez-Luño en su obra propedéutica universitaria cumbre: Derechos humanos, Estado de Derecho y Constitución, Tecnos, 9. ${ }^{a}$ edic., Madrid, 2005, passim

31 Juan Masià Clavel: Bioética y religión: una relación ambivalente, Dykinson, Madrid, 2007.

32 Juan Masià Clavel: Bioética y religión, cit., p. 22.

33 Fernández Segado, Francisco (coord.): Dignidad de la persona, Derechos fundamentales, Justicia constitucional, op. cit. Ruiz de la Cuesta, A.: Bioética y Derechos humanos, caps. 1 ("La imprescindible dignidad", de J. M. Panea Márquez, pp. 17-28) y 3 ("El valor vida humana digna", pp. 5978). Id. autor: Ética de la Vida y la Salud, cap. 2 "Paz y salud ambiental presupuestos de una vida digna", pp. $45-67$.
34 Así, por ejemplo: la XIV Cumbre Iberoamericana ha decidido apoyar, a propuesta de Brasil y Argentina, la idea de la "Alianza de civilizaciones" defendida ante la ONU por el presidente Zapatero; en el Diario La Opinión de Tenerife, 21-11-2004, todo ello de acuerdo con tesis anteriormente reflejadas en la llamada "Declaración de Teherán sobre el Diálogo de Civilizaciones", de 1999, y en la subsiguiente "Declaración de Berlin sobre Diálogo y Coexistencia de Civilizaciones y Culturas", 2000.

35 "L'ignorance étant hardie, c'est dans cette méconnaissance de ce qui se fait ailleurs que l'on est le plus fier des belles réussites qui sont les nôtres. C'est ce qui explique le bon accueil reçu par les théoriciens du conflit des civilisations" (Samuel Hutington et Giovanni Sartori). Lorenzo Peña: Pour une philosophie du droit universel, Institut de Philosophie, CSIC, Madrid, <http://jurid.net/lp>.

36 Fouad N. Boustany define la bioética como "La Bioéthique qui étudie l'utilisation des nouvelles techniques pour concilier la recherche scientifique avec la protection de la personne humaine et de sa dignité", en La Bioéthique: Définition et legislation (vid. bibliografia in fine: http://fm.usj. edu. lb/anciens/biolegi.htm), p. 1.

37 El añadido entrecomillado es de nuestra autoría. NB.: En el Mundo árabo-islámico los únicos países que hasta 1999 disponian de un "Comité Consultivo Nacional de Ética" (y Bioética) eran Túnez y Líbano. La Bioéthique: Définition et legislation, op. cit., p. 3.

38 "Le Comité Consultatif National Libanais d'Ethique pour les Sciences de la Vie el la Santé" se réunit chaque mois au Gran Sérail et etudie et pratique les disciplines de pointe (greffe d'organes, procréation, assisté, etc.). "Ce Comité, qui n'a pas de pouvoir exécutif, donne des avis aux Présidents du Conseil des Ministres qui les dirige envers les Ministres concernés pour legislation". Boustany, F.: La Bioéthique definition et Legislation, ibídem.

39 Visible en la calificación profesional de la mayoría de los autores del libro Bioética y Derechos humanos, op. cit., que comprende una neta delimitación de materias, a saber: cap. 1 , a cargo de cuatro juristas y ningún científico; cap. 2, sobre los valores profesionales a cargo de dos médicos patólogos y profesores de bioética y de un jurista; cap. 3, Biotecnología y biojurídica a cargo de cinco juristas exclusivamente; cap. 4, Problemática bioética y biojurídica nuevamente de cinco juristas exclusivamente; y finalmente, el cap. 5, Trasplante y donación de órganos a cargo de dos médicos y dos juristas. En conjunto la proporción y composición de los profesionales bioéticos en España sigue la norma general de la división dicotómica entre científicos y juristas mayoritariamente, propia de Occidente.

40 Análogos resultados se observan también en el libro: Ética de la vida y la Salud, cit., corriendo la primera parte "Bioética y Derechos fundamentales", 4 caps., a cargo de juristas exclusivamente; la 2. ${ }^{a}$ parte, caps. 5 a 8, a cargo paritariamente de juristas y científicos; en cambio la 3. parte, caps. 9-12, formada sólo por científicos frente a la 4. ${ }^{\text {a }}$ parte y apéndice, caps. 13-19, formadas por juristas, salvo cap. 17.

41 Vid., por ejemplo, como prueba evidente la "Composition du Comité International de Bioethique de L'UNESCO (CIB) 2002-2003", de 36 
miembros, y la calificación académico personal de cada uno de ellos, desde el primero, el Dr. Al-Swailem Abdulaziz M. (A. Saudi), "Director del Instituto de Recursos naturales y Medioambiente" y "Miembro de los Comités de bioética islámica y Biotecnología", hasta el último, Prof. J. Stanislav Zartemba (Polonia), pte. de la Comisión de Neurogenética de la Academia de las Ciencias, pasando por España, representada por el Prof. Nombela, profesor de la Facultad de Farmacia de la UCM y expresidente del CSIC; en UNESCO, doc. SHS-2003/WS/14.

42 Juan Masià Clavel: Bioética y religión: una relación ambivalente, cit., p. 24.

43 Vid. definiciones en: "Ética de la vida y la Salud", cap. XI, Principios éticos en la práctica de los cuidados paliativos, pp. 193-201.

44 "Je suis croyant mais profondement laïque, Secretaire Général d'un Comité Consultatif National officiel Libanais d'Ethique (....) essayant d'institutionaliser ce qu'on appelle la 'Bioéthique Laïque', pour les humains en tant que tels et en des termes universellement accessibles". En http:// www.fm.usj.edu. Ibídem: anciens/clonhum.Htm. Otras posturas polémicas y/o disidentes en Die aktuelle Biomedizin aus der Sicht des Islam, op. cit., in bibliograf. in fine, pp. 36 y ss.

45 Boubaker, D.: Douleur et souffrance dans I'Islam, "... Pour nous la vie commence dès la fécondation.... Mais on acquiert le statut de persone humaine dès le 40ème jour", quien cita como disidente ya al médico-filósofo clásico Avicena, recordando que para éste: "L'embryon s'individualise comme personne au 26. ou 27. jour" (otras escuelas hablan del dia 40,80, incluso 120).
46 Vid. bibliograf. In fine: Bioéthique et Jurisprudence islamique, apartado y polémica en torno a "La mort cérébrale", en http://www.fm.usj.edu.lb/ anciens /islam.htm.

47 "Nicht nur die Entscheidungen der Muftis, die unterschiedlichen Rechtsschulen angehören, könen voneinander divergieren, sondern auch die Meinungen innerhalb einer Rechtsschule, wie in den Diskussionen über den Status des Embryos der Fall ist, können sich voeneinander unterscheiden". Ilkilic, I.: Die aktuelle Biomedizin aus der Sicht des Islam, cit. bibliog. in fine, p. 30.

48 Como por ejemplo en los artículos: "Internet favorece la liberación de la mujer dentro del islam", Amina Wadud; "El principal factor de progreso es el diálogo y el intercambio de información", Mujeres, 26-10-

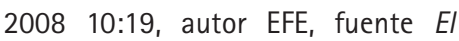
Diario Montañés, en Webislam. Cfr. Sánchez Bravo: "Webs relativas a la salud en la UE", en Ética de la vida y la salud, cit., pp. 305 y ss.

49 Notorio en la obra publicada por la Fundación alemana Konrad Adenauer, citada como modelo de crestomatía interconfesional: Bioethik im christlich-islamischen Dialog, passim.

50 Celebrado en Barcelona, del 27 al 29 de octubre de 2005.

51 El País: "Definiendo el feminismo islámico", Mujer, 16-10-2005. Autor: Abdenur Prado.

52 Mikunda Franco, E.: Derechos humanos y Mundo Islámico, op. cit., espec. cap. VI., Elementos configuradores del Derecho islámico contemporáneo, pp. 161-199.

53 En España especialmente constatables passim en Webalislam.

54 Vid. por ejemplo el "Código de la familia o Moudawanna marroquí", de 2004, o el homónimo argelino.
55 Veamos algunos datos de la Moudawanna actual no sin reservas: "La polygamie, tout en restant autorisée, devient plus difficile. Le consentement de la première femme devient obligatoire, ce qui n'est pas une obligation en islam./L'obligation de l'époux de maintenir sa femme est celle de la femme d'obéir à son époux sont éliminées est tous les deux sont obligés de s'aider et de se respecter mutuellement. II est maintenant exigé que les couples demandent le divorce devant la cour de justice. La simple lettre de répudiation établie devant un responsable religieux ne suffit plus. Lors d'un divorce, le parent qui obtient la garde des enfants conserve le domicile familial. L'âge minimum légal du mariage passe de 15 ans à 18 ans. Le harcèlement sexuel est désormais considéré comme une faute et puni par la loi. Une femme peut se marier sans compter avec le consentement de ses parents. Le mariage des marocains selon les lois d'autres pays est reconnu comme valide". NB.: Datos circulando por la red -Wikipedia- sin garantía.

56 Vid. el libro escrito en coautoría entre Leïla Babès, sociologa, y Tareq Oubrou, rector de la mezquita de Burdeos en un diálogo tenso y encontrado sobre la obligatoriedad del Islam respecto del estatuto jurídico de la mujer. Leïla Babès y Tareq Oubrou: Loi d'Allah, loi des hommes. Liberté, égalité et femmes en Islam, edit. Albin Michel, 2002.

57 NB.: Los días 3, 4 y 5 de noviembre de 2006, Junta Islámica Catalana organizó el II Congreso Internacional de feminismo Islámico, centrado en el tema de la Sharià y los códigos de familia vigentes en países de población musulmana. Datos de la entrevista con Abdenur Prado. 
58 P. Häberle: Teoría de la Constitución como Ciencia de la Cultura (traducción y estudio introductorio: E. Mikunda), edit. Tecnos, Madrid (2001), passim.

59 Christian Starck: "Los fundamentos filosóficos de los Derechos humanos", en Fernandez Segado, Fco. (coord.): Dignidad de la persona, Derechos fundamentales, Justicia constitucional, cit., p. 395 in fine. Cfr. P. Häberle, ib. p. 202.

60 Que, por otra parte, se sigue intentando en instituciones como: "Deklaration des Parlaments der Weltreligionen" -Council for a Parliament of the World's Religions, Chicago-, bearbeitet von Hans KÜNG publiziert im Piper Verlag (München), Continuum Publishing (New York), und SCM Press (London). Unterschrieben am 4 de sept. 1993 in Chicago (USA), Die Prinzipien eines Weltethos I. Keine neue Weltordnung ohne ein Weltethos II. Grundforderung: Jeder Mensch muß menschlich behandelt werden III. Vier unverrückbare Weisungen: 1.Verpflichtung auf eine Kultur der Gewaltlosigkeit und der Ehrfurcht vor allem Leben 2. Verpflichtung auf eine Kultur der Solidarität und eine gerechte Wirtschaftsordnung 3. Verpflichtung auf eine Kultur der Toleranz und ein Leben in Wahrhaftigkeit 4.Verpflichtung auf eine Kultur der Gleichberechtigung und die Partnerschaft von Mann und Frau IV. Wandel des Bewußtseins. Unterschriften: Tan Sri Dato Seri Ahmad Sarji bin Abdul-Hamid, Dr. Qazi Ashfaq Ahmed, Hamid Ahmed, Mazhar Ahmed, Hon. Louis Farrakhan, Dr. Hamid Abdul Hai, Mohammed A. Hai, Dr. Mohammad Hamidullah, Dr. Aziza al-Hibri, Dr. Asad Husain, Dato Dr. Haji Ismail bin Ibrahim, Dr. Irfan Ahmat Khan, Qadir H. Khan, Dr. Abdel Rahman Osman. Schiievertretung:
Prof. Seyyed Hossein Nasr. Sunnivertretung: Imam Dawud Assad, Imam Warith Deen Mohammed, Hon. Syed Shahabuddin.

61 "Posibilidad de una teoría multidimensional del Derechos islámico como elemento aglutinador, inter subjetivo, del polimorfismo jurídico islámico", en Mikunda Franco, E., Derechos humanos y Mundo islámico, cap. 6, op. cit., pp. 170 y ss.

$62 \mathrm{Vid}$. nuestra propuesta teórico-metodológica para el análisis y comprensión de textos en materias de derechos humanos en el Mundo islámico en función de sus conceptos culturales, en cuanto a la terminología (prototexto, metatexto y transtexto) y su metodología (como tales conceptos respecto de su aplicación en dos etapas) ya que son especialmente útiles en materias propias de la bioética, también regionalizada por las escuelas jurídicas islámicas contemporáneas existentes en el planeta; en Derechos humanos y Mundo islámico, cit., pp. 192-195.

63 Vid. BOE 16-10-1997, n. 248 y Aranzadi: n. ${ }^{\circ} 2470$, pp. 6392 a 6403 in extenso.

64 Así, p. ej., la Comunicación de Dinamarca sobre la reserva de las Maldivas (BOE 16-10-1997, n. ${ }^{\circ} 248$, p. 6392); sobre la reserva de Kuwait (Ibíd., p. 6393); sobre el sufragio de los varones; sobre la reserva de Malasia de reenvío a la Sharià (ib.). Otro tanto puede decirse de Austria contra la objeción de Brunei respecto de la Convención sobre los derechos del niño (ibíd. p. 6396); Irlanda contra la reserva de Brunei alegando "falta de claridad específica" (ibíd. p. 6398); Finlandia contra la reserva de Oman, especialmente en cuanto a la elección de religión por un niño (ibíd. p. 6398).
65 Diario de Sevilla, del 11-10-2001, p. 12.

66 Modelos explicitados en "Gemeinislamisches Verfassungsrecht", en JÖR, Nr. 51, pp. 51-79 (2003), cit.

67 Vid. referente a España: Joaquín Brage Camazano: "Breves reflexiones sobre una posible regulación global por ley de las 'opciones de conciencia'", pp. 101-124, en María J. Roca, Opciones de conciencia. Propuestas para una ley, Tirant lo Blanc, Valencia, 2008, pp. 101-124.

68 Algo que ya ha sucedido ante los relatos de Sodoma y Gomorra por parte de colectivos de homosexuales, que se sienten ofendidos por el trato "discriminatorio" de tales textos histórico-religiosos en lo referente a su forma de interpretar la ética sexual subyacente a los mismos (prensa).

69 Así por ejemplo: La Declaración Bioética de Gijón. I Congreso Mundial de Bioética (Gijón, España, 2000) adoptada al final del Congreso Mundial de Bioética (Gijón, España, 20-24 de junio de 2000), en la que el Comité Científico de la Sociedad Internacional de Bioética (SIBI) insiste en que la ciencia y la tecnología deben tomar en consideración el interés general. Cfr. "Convenio de Oviedo de 1997" o "Convenio para la protección de los Derechos humanos y la dignidad del ser humano con respecto a las aplicaciones de la Biología y de la Medicina", así como la "Declaración Universal sobre el Genoma y los Derechos Humanos", de 11 de noviembre de 1997; vid. Introducción a Ética de la vida y la Salud, cit., p. 13 y ss.

70 Mikunda Franco, E.: "Aspectos de Bioética en el Mundo islámico contemporáneo", cap. XIX de Ética de la vida y la salud, op. cit., pp. 315341. 
71 Mikunda Franco,E.: Derechos humanos y Mundo Islámico, op. cit., espec. apéndice doc., pp. 213 y ss.

72 "Estoy consciente de que algunos consideran la preocupación por los derechos humanos como un lujo de los países ricos para el cual África no está listo. Sé que otros la tratan, si bien no como un complot, sí como una imposición del Occidente industrializado. Yo considero este tipo de opinión muy degradante, degradante del anhelo por la dignidad humana que vive en todo corazón africano". Koffi Annan, Discurso ante la Asamblea Anual de los Jefes de Estado y Gobierno de la Organización de la Unidad Africana, Harare, 2 de junio, 1997, Doc. SG/ $\mathrm{SM} / 6245$.

73 Extracto del Discurso de Kofi Annan en la Universidad de Teherán en el día de los Derechos Humanos, 10 de diciembre, 1997, fuente doc. SG/ SM/6419. NB.: La problemática de llegadas masivas en pateras a Europa bien podría tener sus raíces en éste y otros discursos similares pronunciados sin calibrar las posibles consecuencias de tomar al pié de la letra frases como la siguiente: "Les otorga el poder para cruzar cualquier frontera, escalar cualquiera muro, desafiar cualquier fuerza".

74 Kofi Annan: Conferencia de prensa en la Cumbre de la Organización de la Conferencia Islámica, Teherán, 11 de diciembre, 1997.

75 Artículo 30.: "Nada en la presente declaración podrá interpretarse en el sentido que confiere Derecho alguno al Estado, a un grupo o a una persona para emprender y desarrollar actividades o realizar actos tendentes a la supresión de cualquiera derechos o libertades proclamados en la presente declaración".
76 Vid. apéndice documental de "Derechos Humanos y Mundo islámico", cit., pp. 213 y ss.

77 "Ninguna disposición de la presente Declaración podrá interpretarse como si confiriera a un Estado, grupo o individuo derecho alguno a emprender actividades o realizar actos que vayan en contra de los derechos humanos, las libertades fundamentales y la dignidad humana". Declaración Universal sobre el Genoma Humano y los Derechos Humanos, aprobada en fecha de 11 de noviembre de 1997. UNESCO.

78 Artículo 12: Respeto de la diversidad cultural y del pluralismo. "Se debería tener debidamente en cuenta la importancia de la diversidad cultural y del pluralismo". No obstante, estas consideraciones no habrán de invocarse para atentar contra la dignidad humana, los derechos humanos y las libertades fundamentales o los principios enunciados en la presente Declaración, ni tampoco para limitar su alcance". Artículo 13: Solidaridad y cooperación. "Se habrá de fomentar la solidaridad entre los seres humanos y la cooperación internacional a este efecto". Declaración Universal sobre el Genoma Humano y los Derechos Humanos, cit.

79 Discurso ante la Cumbre de la Organización de la Conferencia Islámica, Teherán, 9 de diciembre de 1997. Fuente: SG/SM/6418.

80 Winfried Hassemer: "Tolerancia religiosa en el Estado de Derecho;el paradigma del Islam", en Fernández Segado, Francisco, Dignidad de la persona, Derechos fundamentales, Justicia constitucional, op. cit., pp. 559-597.

81 P. Häberle: "La dignidad como 'Grundnorm' del ordenamiento y fundamento de la comunidad estatal", en Fer- nández Segado, Francisco, Dignidad de la persona, cit., pp. 173-237.

82 K. Annan: Mensaje en el Día Internacional para la Abolición de la Esclavitud, 2 de diciembre de 1997. Fuente: SG/SM/6411.

83 Datos en la Introducción de A. Ruiz de la Cuesta a Ética de la vida y la salud, op. cit., pp. 13-17.

84 Mikunda Franco, E.: "Derechos humanos y Mundo Islámico", cit., cap. 2, Tipología de los derechos humanos en el Mundo islámico en clave filosóficojurídico comparatista, pp. 48-64.

85 Cfr. "Bioética y valores constitucionales", en Bioética y Derechos humanos, cit., pp. 79 y ss.

86 P. Häberle puede ser considerado, quizás, el autor mejor representativo del pensamiento iusfilosófico-constitucional occidental en cuanto a la insistencia repetitiva en sus obras de la nota de "inmanencia" como característica del Derecho constitucional contemporáneo occidental; vid. P. Häberle: Verfassungslehre als Kulturwissenschaft, D \& H, Berlin, 1998, pp. 429, 604. Traducción y Estudio introductorio E. Mikunda: Teoría de la Constitución como Ciencia de la Cultura, Tecnos, Madrid, 2001.

87 El laicismo de Túnez serviría como ejemplo palmario para documentar el mayoritario rechazo que sufre en el seno de los pensadores juristas islámicos, quienes no obstante respetan su capacidad de autogobierno y de exégesis de los textos islámicos pese a mostrar su disconformidad, calificándolo de erróneo. Otros ejemplos teóricos en "The First International Conference on islamic Medicine" (1981), "First International Conference on Bioethics in Human Reproduction Research in the Muslim World" (1991), "The Fiq Council of North America" (2001), cit. en Die 
aktuelle Biomedizines aus der Sicht des Islam, op. cit. en bibliogrf. in fine, pp. 34-35.

88 Artículo 15. "A fin de promover un lenguaje universal para la Bioética, deberá hacerse un esfuerzo por armonizar y unificar los conceptos que tienen actualmente terminologías diferentes. El acuerdo en este ámbito se hace indispensable desde el respeto a las identidades socioculturales". Declaración Bioética de Gijón, 2000, corolario final del Congreso Mundial de Bioética (Gijón 20-24 de junio de 2000).

89 Artículo 10 de la Declaración Bioética de Gijón, 2000: "La creación de individuos humanos genéticamente idénticos por clonación debe prohibirse". Vid. "Condicionante ético en investigación y experimentación con células madre: motor y freno de una regulación internacional sobre la clonación humana", en Bioética y Derechos humanos, cit., pp. 209 y ss.

90 Cfr. "clonación de células embrionarias", en Ética de la vida y la salud, cit., p. 265. y "La clonación humana: problemas éticos", en Bioética y Derechos humanos, cit., pp. 193 y ss.

91 Cf. "Suicidio y eutanasia", en Bioética y Derechos humanos, cit., pp. 315 y SS.

92 Cf. "Artículo 3: Dignidad humana y derechos humanos. 1. Se habrán de respetar plenamente la dignidad humana, los derechos humanos y las libertades fundamentales. 2. Los intereses y el bienestar de la persona deberian tener prioridad con respecto al interés exclusivo de la ciencia o la sociedad. En Declaración Universal sobre Bioética y Derechos Humanos, cit.

93 Cf. "Principios Éticos en la práctica de los cuidados paliativos", en Ética de la vida..., cit., pp. 193 y ss.
94 Vid. "Conclusiones: interpretación constitucional y bioderecho", en Ética de la vida, cit., pp. 39-42.

95 Cf. "Soluciones jurisprudenciales y de jurisprudencia comparada", en Ética de la vida y la salud, cit., pp. 279 y ss. (NB: Se trata de casos de objeción de conciencia de pacientes frente a tratamientos médicos.)

96 Cf. "Una definición polémica: Un problema biojurídico", en Ética de la vida y la salud, cit., p. 70, y "Ëtica y responsabilidad profesional del médico", en Bioética y Derechos humanos, cit., pp. 95-104.

97 Cf. "Riesgos de medicina genética ¿Hacia una nueva eugenesia?", en Ética de la vida..., cit., pp. 105.

98 Cf. "Reflexiones jco-penales sobre interrupción voluntaria del embarazo", de Monge Fernández, A., en Bioética y Derechos humanos, cit., pp. 245 y ss.

99 Cf. "Ley 5/2003 de 9 de octubre, de declaración de voluntad vital de Andalucia", en Ética de la vida y la salud, cit., pp. 241 y ss.

100 Cf. "Eutanasia activa y principio de autodeterminación", en Bioética y Derechos humanos, cit., pp. 277 y ss.

101 Cf. "Objeción de conciencia del paciente a tratamientos médicos", en Ética de la vida y la salud, cit., 271 y ss.

102 Cf. "El derecho a decidir sobre la propia muerte", en Ética de la vida y la salud, cit., pp. 27-32.

103 Cf. "La protección penal del Derecho a la salud", en Ética de la vida y la salud, cit., pp. 219 y ss.

104 Cf. "El Ilamado modelo español. Principios y requisitos de la normativa española", en Ética de la vida y la salud, cit., pp. 260.

105 Cf. "El trasplante de donante vivo", en Bioética y Derechos humanos, cit., pp. 361 y ss.
106 Cf. "El trasplante de órganos en la legislación española", en Bioética y Derechos humanos, cit., pp. 345.

107 Cf. "Investigación en células madre", en Ética de la vida y la salud, cap. 8, cit., pp. 139 y ss.

108 Cf. "Descubriendo los límites. ¿Respetar la biodiversidad?", en Ética de la vida y la salud, cit., pp. 97 y ss.

109 Cf. "La utilización de células troncales con fines terapéuticos debe permitirse siempre que la obtención de esas células no implique la destrucción de embriones". Art. 10 in fine de la Declaración Bioética de Gijón, 2000, cit.

110 Coincide con la ética católica, al igual que respecto de los llamados "hermanos terapéuticos", ya que la definición legal de pre-embrión carecería de apoyo científico y filosófico al tratarse de una ficción legal a tenor de la cual aun después de la fecundación, habría en el desarrollo embrionario una fase no humana, durante la cual el embrión humano no merecería el respeto debido a los seres humanos. El "término preembrión" está hoy totalmente en desuso dentro de la literatura científica especializada, siendo la embrióloga Anne McLaren quien lo acuñó. Más tarde explicó las razones -ajenas a la ciencia- por las que el Comité Warnock lo introdujo en su informe. Cf.: A. McLaren, "Prelude to Embryogenesis", en The Ciba Foundation (ed.), Human Embrio Research: yes or no?, Londres, 1986, pp. 5-23.

111 Cf. "Los xenotrasplantes", en Ética de la vida y la salud, cit., pp. 263.

112 Cf. "La intimidad genética, perspectivas desde la autonomía individual", en Bioética y Derechos humanos, cit., pp. 225 y ss. 
113 Cf. "El derecho de la mujer a decidir su maternidad", en Bioética y Derechos humanos, cit., pp. 263 y ss.

114 Cf. "El Derecho a la intimidad en el ámbito biomedicina", en Bioética y Derechos humanos, cit., pp. 105.

115 Cf. "El Derecho a la reproducción", en Ética de la vida y la salud, cit., pp. 35-39.

116 Cfr. "Sociedad del conocimiento, biotecnología y biodiversidad", en Bioética y Derechos humanos, cit., pp. 165 y ss.

117 El Hadiz dice: "La création d'une personne dans le ventre de sa mère passe par les étapes suivantes: 40 jours sous forme de terre, 40 jours puis sous forme d'adhérence, puis 40 jours sous forme d'une bouchée; puis Dieu lui envoie un archange qui lui ensouffle I'Esprit". En Bioéthique et Jurisprudence islamique, op. cit., p. 20.

118 Vid. bibliografia in fine: Diagnostic prénatal: "En matière de diagnostic prénatal, la Bioéthique musulmane se refère a deux sources: la Philosophie spéculative (KALAM) et la doctrine (FIOH) musulmane" ... "Les cellules embryonnaires ne peuvent en aucun cas etre assimilées quelque soit leur stade à des objets, ou a des choses" ... "Nul n'a le droit de disposer de la vie d'autrui ni d'en modifier la destinée" (Corán, IV-29, VI-151)...

119 Sass, Hans-Martin y Ilkilic, Ilhan: Die aktuelle Biomedizin aus der Sicht des islam. Ein Gutachten des Max-Delbrück-Centrums für molekulare Medizin. Universität Tübingen. Interfakultäres Zentrum für Ethik in den Wissenschaften (IZEW), Berlin Buch, 2002, Zusammenfassung: S. 1. Ibídem "Zentral ist bei der Beurteilung des moralischen Status des Embyos die Bese- elung und Ihre Implikationen usf" ... "Entscheidend für die Schutzwürdigkeit bzw. nicht-Schutzwürdigkeit des Embryos".

120 "The remaining embryos would be either beeb indefinitely or destroyed. If these embryos were trated as full human, it would be forbideden to produce them in excess and to destroy them later. No one treats them as humans. We disagree with the Catholic position that it is equivalent to infanticide". En Islamic perspective on Stem Cells Research 2/27/02. Education Religious. Art. Ref: IC0202-404. Dr. Muzammil Sidiqqi. Islam City.

121 Una visión condensada de posturas católicas al respecto en: Bioethik im interreligiösen Dialog, cit. Cfr. "Producir seres humanos en el laboratorio es inmoral, porque la producción no es un acto personal como el requerido por la convocatoria de una nueva persona a la existencia", en Algunas orientaciones sobre la ilicitud de la reproducción humana artificial y sobre las prácticas injustas autorizadas por la ley que la regulará en España, 86. ${ }^{\text {a Asamblea }}$ Plenaria de la Conferencia Episcopal Española, Madrid, 30 de marzo de 2006.

122 Revue du Liban, n. ${ }^{\circ}$ 58, www.rdl. com.lb.htm.

123 "Le problème du clonage n'est pas avez Dieu, mais avec la coutume", "La croyance passe par la science, non par l'ignorance", en http:// www.fm.usj.edu.lb/anciens/fadlallah.htm, p. 2.

124 Ver "Le clonage humain reproductif", en wwwfm.usj.edu.lb/anciens/ clonhum.htm, pp. 3-4.

125 Fatwa de Sir Hamza Boubaker: Point de vue de I'Islam sur l'Euthanasie, cit. en bibl. in fine.
126 "I diritti del feto si basa sul fatto che finchè non si e svilupato il sistema nervoso, non si può parlare di individuo umano, a maggior raggione parlando di embrione, del'ovulo e dello spermatozoo". Autor anónimo, en internet, bajo: Cenni sull'Etica e sulla Bioetica nell'Islam, en www.puntosufi.it/84 dist.Htm. Cf. "El embrión humano merece, pues, el respeto debido a la persona humana, porque 'no es una cosa ni un mero agregado de células vivas, sino el primer estadio de la existencia de un ser humano: Todos hemos sido también embriones", en 76 Asamblea Plenaria de la Conferencia Episcopal Española, La familia, santuario de la vida y esperanza de la sociedad (27 de abril de 2001), n. 109.

127 Ver en este sentido: Forum internacional de Bioéthique, Rome, 21 de octobre de 2002, Zenit. org. www. fm.edu. Il. anciens/blorome.htm.

128 K. Annan: Discurso en el evento de caridad enfrentando a la historia y a nosotros mismos, Nueva York, 14 de octubre de 1997. Fuente: SG/ SM/6359.

129 K. Annan: "La violencia contra la mujer se ha vuelto la forma de violación de los derechos humanos más penetrante, que no respeta distinción alguna de geografía, cultura o riqueza". Discurso ante la Asamblea General, en la inauguración de su quincuagésima segunda sesión, Nueva York, 22 de septiembre de 1997. Fuente: SG/SM/6334.

130 El País: "Definiendo el feminismo islámico", Mujer, 16 de octubre de 2005. Autor: Abdenur Prado.

131 El País, ibídem.

132 El País, ibídem.

133 Incluso a nivel de relaciones sexuales, como abiertamente se lee en 
el libro del profesor sociólogo tunecino Boudhiba, A.: La sessualità nell'Islam; a fortiori en el del filósofo laicista Darius Atighetchi: "La morale secondo il Corano", Islam, musulmani e Bioetica (A. Giornalismo Scientifico).

134 Como por ejemplo las de cuño kantiano, tan relevantes cultural y constitucionalmente en Occidente, como nos habla José Manuel Panea en Bioética y Derechos Humanos, cap. 1, cit., p. 21 al presuponer que: "Por tanto, la dignidad es la clave de bóveda de todo el edificio moral kantiano $y$, nos atrevemos a decir, de 'toda moral' que aspire a desarrollarse dentro del horizonte de lo humano". Cfr. La influencia de Kant en el universalismo actual, ibídem, pp. 29 y ss.

135 Ilkilic, I.: Die Bioethik aus der Sicht des Islam, op. cit., pp. 43 y ss.

136 "Das Judentum vertritt möglicherweise die liberalste Position, indem nach jüdischer Auffassung das Leben mit der Geburt beginnt und daher in der Forschung mit Embryonen der erhoffte medizinische Nutzen der Potentielle Nachteile gestellt wird", Dehn, U. en Bioethik in interreligiösen Dialog, cit., p. 3.

137 "Der Buddismus betrachtet zwar Leben als Kontinuum und insofern als Merkmal des Embryos, sieh aber die Forschung mit Embryonen als Verletzung des Gebots der Gewaltenfreiheit.Im Hinduismus wird das Lebensbeginn auf die Empfängnis datiert, jedoch in Indien ausmedizinpolitischen Gründen in den ersten 14 Tagen zugelassen". Dehn, U. en Bioethik in interreligiösen Dialog, ibídem.

138 Cfr. J. Pablo II: Carta Encíclica Evangelium vitae, 60. Cf. 57. Benedicto XVI, en Discurso al Congreso
Internacional "Sobre el embrión humano en su fase preimplantatoria", organizado en Roma en febrero de 2006 en la "Pontificia Academia para la Vida", declaraba expresamente que la obligación de tutelar la vida humana inocente enseñada por la Evangelium vitae, "se refiere también al inicio de la vida de un embrión, incluso antes de ser implantado en el seno materno" (27 de febrero de 2006).

139 Como por ejemplo sería en su caso la Declaración bioética de Gijón, 2000.

\section{BIBLIOGRAFÍA}

\subsection{Selección de fuentes especializadas en bioética islámica}

Boustany, N. Fouad: La Bioéthique: Définition et Légis/ation, en http://www. fm.usj.edu.lb/anciens/biolegi.thm.

Boubakeur, Dalil en internet bajo: Etique biomedicale en Islam; Bioéthique et Jurisprudence islamique; Douleur et souffrances dans I'Islam; L'Islam, la sexualité et la prevention du SIDA; Islam et SIDA; Contraception et préservatifs en Islam; L'Embryon dans I'Islam; L'Utilisation des techniques genetiques,Diagnostic prénatal, diagnostic pré-implantatoire et problèmes étiques; Diagnostic prenatal et Islam; Fin de vie-Arret de la vie-Euthanasie; Euthanasie; L'obligation de se soigner en Islam; Miracles et guérisons miraculeuses en Islam; Soins palliatifs et tradition islamique: Journée nationale de lutte contre le cancer; XenogreffeBioethique islamique; Etique et transplantation en Islam.

Boubakeur, Hamza: "FATWA: Point de vue de I'Islam sur L'Euthanasie" (Reponse à une consultation juridico-theologique islamique de Son. Excellence Sir Hamza Boubakeur).

Ayatola Sayyed Mohamed Hussein FadlaIlah (2002): Conférence sur la Bioétique-Islam, http//www.fm.usj.edu/lb/ anciens/fadlallah.htm.

Forum International de Bioéthique, Rome (21 de octobre de 2002). Zenit. Org.: Reflexions sur le clonage humain reproductif", en http/www. fm.usj.edu/ Ib/anciens/clonhum.htm.

Forum International de Bioéthique, Rome (21 de octobre de 2002). Zenit. Org.: La Bioéthique au Liban, Prof. Fouad Boustany. En http//www.fm.usj.edu/ lb/anciens/biolib.htm.

Siddiqi, Muzammil (2002): "An islamique perspective on Stem Cell Research", 2/27/2002, Education Religious, art. Ref. IC0202-404. Islamcity.

Sass, Hasns-Martin y Ilkilic Ilhan (2002): Die aktuelle Biomedizin aus der Sicht des islam. Ein Gutachten des MaxDelbrück-Centrums für molekulare Medizin. Universität Tübingen. Interfakultäres Zentrum für Ethik in den Wissenschaften (IZEW). Berlin Buch.

Dehn, Ullrig (2004): Bioethikim interreligiösen Dialog. Informationen. Materialdienst 11/2004, Evangelische Zentralstelle für Weltanschauungsfragen. En: http:// www.ekd.de/ezw.print/40027.htm.

Eich, Thomas y Reifeld, Helmut (Hrsg.) (2004): Bioethik im christlich-islamischen Dialog. Druck von Konrad Adenauer-Stitfung e.V. 2004.

Anonimo: Cenni sull'Etica e sulla Bioetica nell'Islam, en http://www.puntosufi. it/84 dist.htm.

W.AA. (2002-2003): Composition due Comité International de Bioéthique de I'UNESCO (CIB), -SHS-2003/WS/14-. París, 30-04-2003. Original: francés/ inglés. W.AA. (2002): Kulturübergreidende Bioethik. Vorasussetzungen, Chancen,Probleme. DFG. 


\subsection{Derechos humanos y bioética en doctrina y Constitución: perspectivas laico-occidentales}

Ruiz de la Cuesta, A. (coord.) (2008): Ética de la vida y la salud. Su problematica biojurídica, edit. Secretariado de Publicaciones de la Universidad de Sevilla, ISBN: 978-84-472-1116-6, 341 pp.

- (2005): Bioética y Derechos humanos: implicaciones sociales y jurídicas, edit. Secretariado de Publicaciones de la Universidad de Sevilla, ISBN. 84-4720871-0, 406 pp.

Fernández Segado, Francisco (coord.) (2008): Dignidad de la persona, Derechos fundamentales, Justicia constitucional y otros Estudios de Derecho Público, edit. Dykinson, Madrid, ISBN: 978-84-9849-151-1, 1.209 pp.

Pérez-Luño, A. E. (2006): La tercera generación de Derechos humanos, edit. Thomson, Aranzadi. 2006.
- (2005): Derechos humanos, Estado de Derecho y Constitución, Tecnos, 9. ${ }^{a}$ edic., Madrid, 659 pp., ISBN: 84309-4284-X.

\subsection{Bibliografía contextual del autor del presente trabajo}

Mikunda Franco, E. (2008): "Aspectos de Bioética en el Mundo islámico contemporáneo: Aproximación a un estudio iusfilosófico comparatista intra islámico en un contexto multicultural mundial en fase de globalización", capítulo XIX, del libro Ética de la vida y la salud. Su problemática biojurídica, Antonio Ruiz de la Cuesta (coord.), edit. Secretariado de Publicaciones de la Universidad de Sevilla, ISBN: 97884-472-1116-6, pp. 315-341.

- (2001): Derechos humanos y mundo islámico, Servicio de Publicaciones, Universidad de Sevilla, 285 pp., ISBN: 84-472-0649-1. Agotada 1.a edic.
(1. ${ }^{a}$ reimpresión en diciembre de 2003).

- (2003): "Gemeinislamisches Verfassungsrecht...", en J.Ö.R. Neue Folge, Nr. 51, pp. 51-79. Traducción parcial al italiano: "Diritto costituzionale comune islamico. Un'indagine comparata sui testi costituzionali di alcuni Stati islamici", en Tradizioni culturali, Sistemi Giuridici e Diritti Umani nell'area del Mediterraneo: Colombo V. (Gozzi, G., a cura di), col.: Democrazie, Diritti, Costituzioni, ed. II Mulino, 2004, ISBN: 88-15-09656-6; pp. 261-288.

- (2002): "Los Derechos Humanos en el Mundo Islámico: Su Dimensión Cultural en el siglo XXI" y "El Derecho Islámico Contemporáneo en su Dimensión Constitucional", ambos artículos en Cuadernos Electrónicos de Filosofía del Derecho, n. ${ }^{\circ}$ 5/2002.

- (2001): "Política y realidad jurídica en el Islam", El Diario de Sevilla, 11-102001; y "La Ley Islámica es la clave", El Diario de Sevilla, 14-10-2001. 